\title{
Automated System to Measure the Carbonate Concentration of Sediments
}

\author{
by \\ Dorinda R. Ostermann, Darrell Karbott and W.B. Curry
}

February 1990

Technical Report

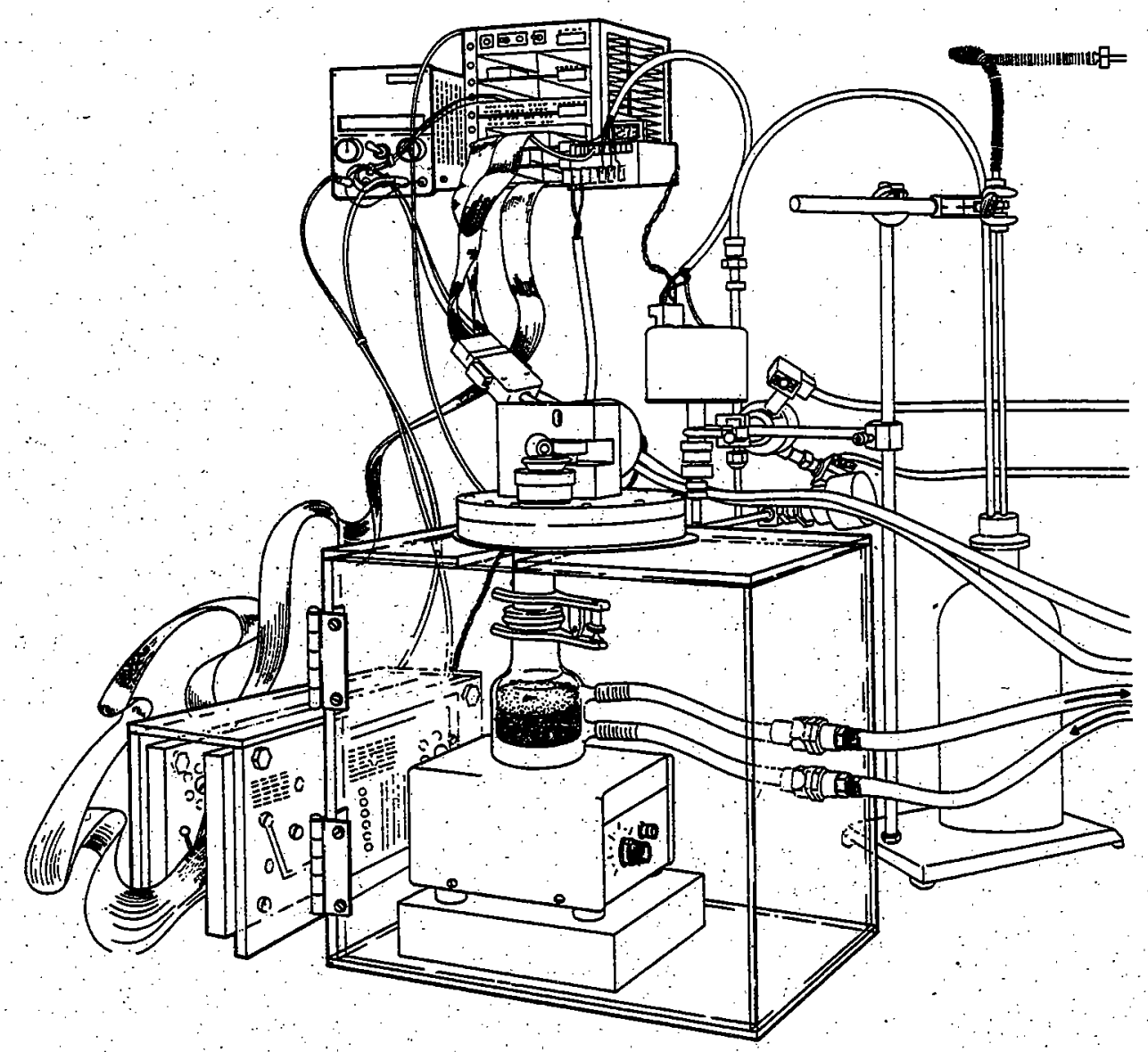




\title{
WHOI-90-03
}

\section{Automated System to Measure the Carbonate Concentration of Sediments}

by

\author{
Dorinda R. Ostermann, Darrell Karbott and W.B. Curry \\ Woods Hole Oceanographic Institution \\ Woods Hole, Massachusetts 02543
}

February 1990

\section{Technical Report}

Funding was provided by the National Science Foundation through Grant Nos.

OCE 85-11014 and OCE 88-13307.
Reproduction in whole or in part is permitted for any purpose of the United States Government. This report should be cited as: Woods Hole Oceanog. Inst. Tech. Rept., WHOI-90-03.

Approved for publication; distribution unlimited.

\section{Approved for Distribution:}

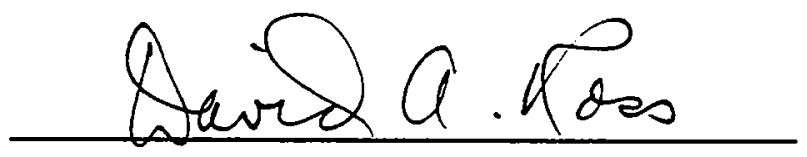

David A. Ross, Chairman

Department of Geology \& Geophysics 


\section{Contents}

1 INTRODUCTION

2 HARDWARE

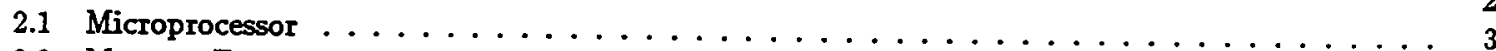

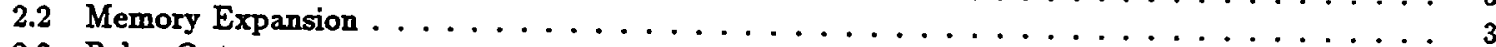

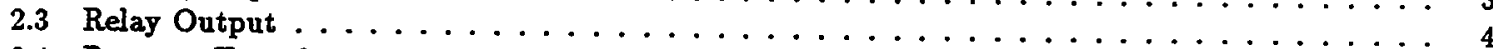

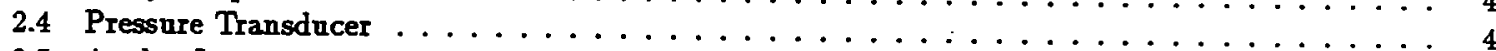

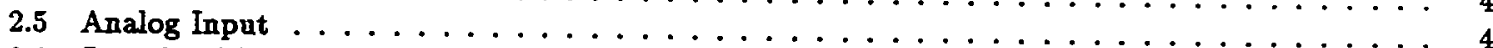

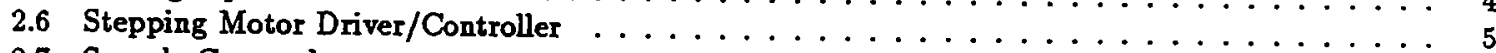

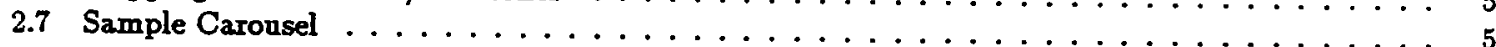

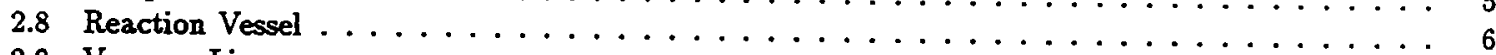

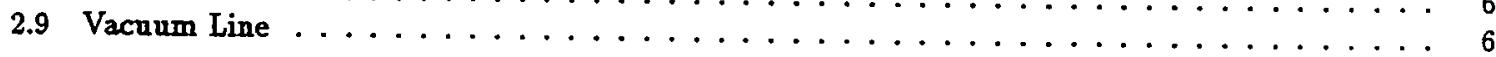

3 SOFTWARE

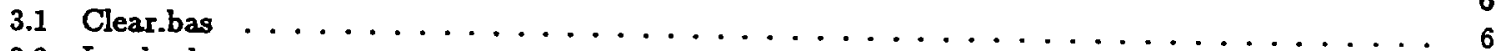

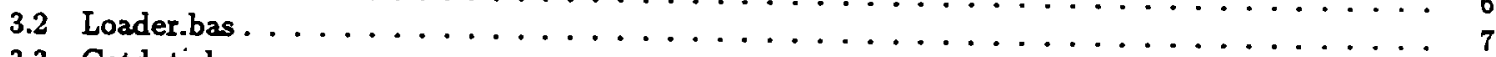

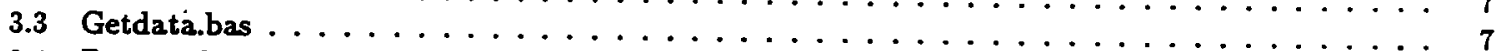

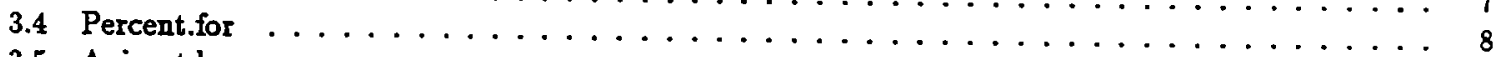

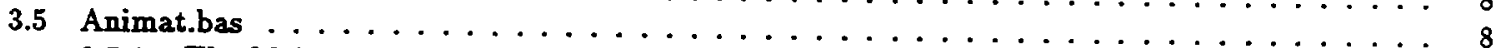

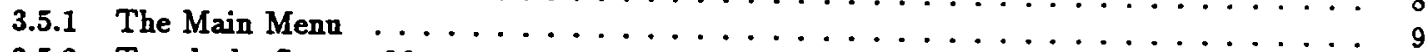

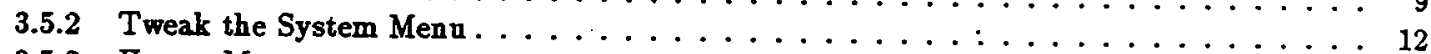

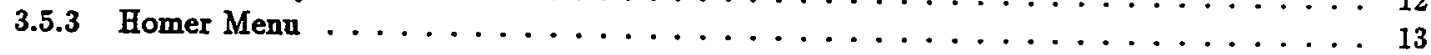

4 OPERATIONS

5 REFERENCES 17

6 FIGURES

6.1 Antomated carbonate system schematic. . . . . . . . . . . . . . . . . . a

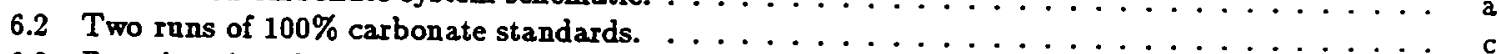

6.3 Reaction time for samples of varying carbonate content. . . . . . . . . . . . . . . . . . .

6.4 Reaction time for samples of low carbonate content. . . . . . . . . . . . . . . . . . . e

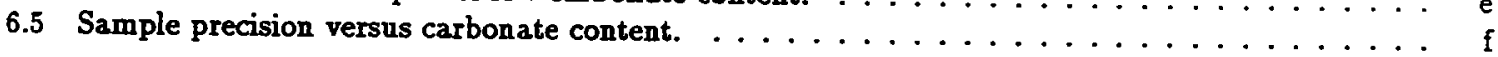

7 APPENDICES

7.1 Board jumpering specifics. . . . . . . . . . . . . . . . . . . . . . i

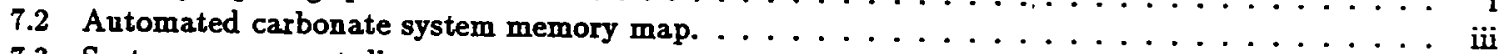

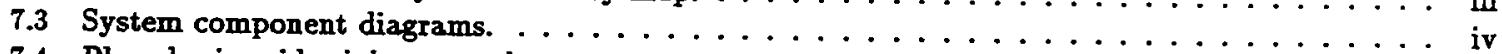

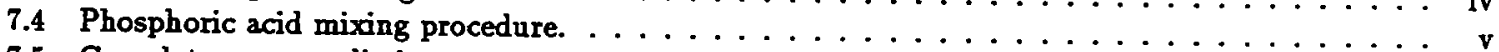

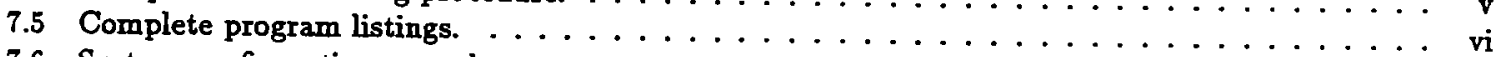

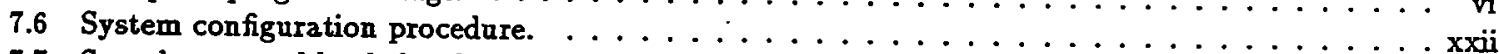

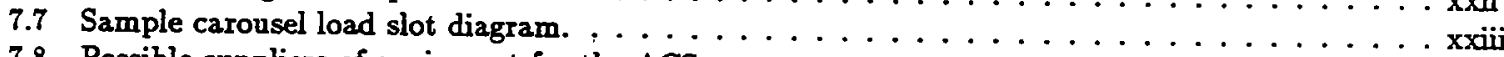

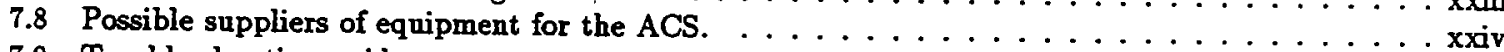

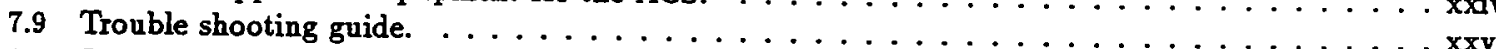

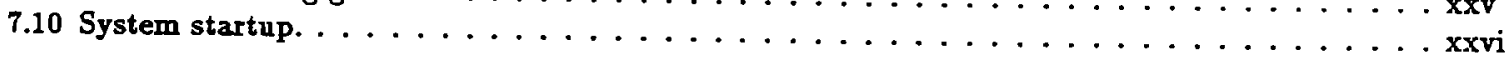




\section{INTRODUCTION}

We have developed a computer controlled system to measure the calcium carbonate content of sediment samples. A menu driven program controls the analysis of each sample. The system first communicates with a Mettler digital balance to record the weights of the 40 samples which must be loaded into each run. The sample boats are next loaded into the sample carousel which is then sealed from the atmosphere. The system is first pumped down to a vacuum of 0.04 torr. The valve to the pump closes and the stepping motor turns the carousel, moving a sample boat over the delivery slot and dropping the sample into $80^{\circ} \mathrm{C} 100 \%$ phosphoric acid under vigorous spinning action. During the reaction, carbonate is evolved into $\mathrm{H}_{2} \mathrm{O}$ and $\mathrm{CO}_{2}$ and the resulting pressure change within the closed system is measured by a pressure transducer and recorded into memory next to the sample identification and sample weight. The system is pumped once again to 0.04 torr and the process continues until all 40 samples have been analyzed. The data can then be uploaded and converted to percent carbonate values using a regression line produced from multiple analyses of varying weights of a $100 \%$ carbonate standard. Precision of the system, based upon 120 replicate analysis ranges from $0.49 \%$ to $0.88 \%$.

\section{HARDWARE}

We set out to develop an easy-to-use automated carbonate system which was inexpensive and microprocessor controlled. We based the system on the STD bus because of its modular control-oriented system design and because of the wide availability of plugin cards for specific control applications. With a minimal amount of rejumpering (see Appendix 1), the boards were snapped into the card cage, and connected to the balance, terminal, stepping motor and pressure transducer. The automated carbonate system (ACS) consists of the following major components, and is diagrammed in Figure 1. 


\subsection{Microprocessor}

The VERSALOGIC@ VL-7806 Z80 microprocessor is used in this application. The STD bus compatible board features a flexible memory mapping option which allows a mixture of memory devices to be used in the system. In this system we use a $64 \mathrm{~K}$ memory expansion board in addition to the memory contained on the Z80 board. Appendix 2 details the memory map of the $\mathrm{Z} 80$ processor as configured in this system. The Z80 board also features two RS232 serial I/O ports. We use port B to communicate with the METTLER AE100 balance through a bi-directional interface. Port A is connected to a NEC APC II computer which is used as a terminal for the $\mathrm{Z80}$ processor and to upload the data from the carbonate analyzer. A $C 4 B A S I C \bigcirc$ 8K ROM is plugged into socket M0 on the VL-7806 processor card. The $C \& B A S I C$ language which runs the automation is oriented to process control tasks and includes special statememts for $\mathrm{I} / \mathrm{O}$ device interface. It is designed to run programs directly from ROM storage and has an operating system, NOVOS, which utilizes RAM nonvolatile memory. This allows development, testing, backup, copying and transferring of $C_{4} B A S I C$ programs in a totally diskless system.

\subsection{Memory Expansion}

The large size of the automation program made it necessary to expand the memory of the system using a VERSALOGIC VL-7709 memory card. The board provides 16-bit addressing for use with the $\mathrm{Z} 80$ processor. The system as configured uses a total of $48 \mathrm{~K}$ of RAM, three $8 \mathrm{~K}$ chips on the $\mathrm{Z} 80$ board and three $8 \mathrm{~K}$ chips on the memory board. This $48 \mathrm{~K}$ of memory may be allocated for storage area and development RAM in any proportion using the system SETUP command (see Appendix 6). However, the sum of the number of Kbytes for storage and development RAM must not exceed $47 \mathrm{~K}$. This reserves $1 \mathrm{~K}$ at the top of memory (\&DC01-\&DCFF) for critical machine language subroutines. 


\subsection{Relay Output}

Solenoid actuators for the pneumatic valves are controlled by a VERSALOGIC IPI-2 eight channel relay output card. The individual relays are powered by a 28 VDC source and the channels we use are activated through address \&96. Circuitry is provided to drive eight LED indicators at the edge of the board which display the current on or off state of each channel.

\subsection{Pressure Transducer}

A 0-100 torr BARATRONC absolute pressure transducer is used as the system pressure sensor. We chose this particular transducer because it is capable of withstanding high overpressure conditions and it is highly resistant to corrosive environments. We connected the transducer and the analog input board through a $10 \mathrm{~K}$ reostat (see Appendix 3A). The reostat reduced the normal 10 volt output range of the transducer to 5 volts, doubling the resolution of the transducer. Careful attention was paid to limiting the internal volume of the reaction vessel and the lengths and internal diameters of the stainless steel tubing, minimizing the overall volume of the system and maximizing the pressure transducer output (see Appendix 3B). A microvoltmeter connected to the transducer externally monitors the pressure within the system.

\subsection{Analog Input}

The VERSALOGIC STD AIN- 1 is an eight channel integrating analog input board compatible with the STD bus. This board uses an integrating conversion technique to perform the analog to digital conversion. The integrating method measures the actual input signal during the conversion giving a much higher accuracy in changing or moving input signals such as found in our system. The integrating conversion is also very noise tolerant. These advantages are a trade off to slower conversion times but because our system is only monitoring one signal during a 5 to 20 minute reaction time, the slower conversion time does not limit this system's efficiency. The analog input board is jumpered to a 5 volt input range. This lower voltage range provides twice the resolution for each measurment $(2.5 \mathrm{mv}$ versus 
$5 \mathrm{mv}$ in the $10 \mathrm{mv}$ range) without affecting stability or conversion time. The one part in 4000 (12 bit) resolution provides a digital pressure unit equivalent to .025 torr. We chose to use the differential input mode for signals that are not referenced to a ground point but are simply a voltage difference between two input wires. This mode is especially beneficial in electrically noisy environments. We communicate with this board via address $\& 70$.

\subsection{Stepping Motor Driver/Controller}

The Matrix Dual Stepping Controller (DSC) and Unipolar Stepper Driver (USD) provide microprocessor control of unipolar stepping motors. A 26-position ribbon cable connects the DSC in the card cage to the USD. The USD converts the DSC output signals to the voltage and current levels required by the stepping motor. The USD receives logic power directly from the DSC which is initialized upon power-up via a software status/command register. These commands include direction of rotation, single versus continuous step mode and the motor speed. The 4-phase stepping motor used in this application is powered by an external 24 VDC power supply connected directly to the USD.

\subsection{Sample Carousel}

A 'lazy susan' designed by R.G. Fairbanks served as the basis for our carousel assembly design. It was modified to our specific application and machined out of 316 stainless steel to resist acid corrosion. A four phase stepping motor is attached to the top of the carousel assembly. The motor turns a set of reducing gears connected to the carousel shaft which is sealed from the atmosphere with two ' $O$ ' rings, allowing the shaft to rotate the sample dispenser under vacuum. The carousel makes one full revolution every 2000 steps of the stepping motor. The sample carousel holds 40 samples which may be loaded through the top assembly by removing an ULTRA-TORR(C) fitting. The top and bottom carousel assemblies are secured together with allen cap screws and are sealed from the atmosphere with an ' $O$ ' ring which fits into a groove in the bottom assembly. 


\subsection{Reaction Vessel}

A glass reaction vessel (see Appendix 3C) is attached to the bottom of the sample carousel assembly with a pinch clamp and is sealed from the atmosphere with an ' $O$ ' ring. The $20 \mathrm{ml}$ phosphoric acid (see Appendix 4 ) within the vessel is maintained at $80^{\circ} \mathrm{C}$ by a circulating water bath and a strong spinning action of a magnetic stir bar.

\subsection{Vacuum Line}

Any pump which can pump down to a vacuum of $10^{-4}$ torr is suitable for use with this system. Large internal diameter 0.25 inch copper refridgeration tubing was used between the valves and the vacuum pump to provide a more efficient initial pump down. Flexible stainless steel tubing was used between the vacuum pump and the oil trap to lessen vibration through the system. ULTRA-TORR fittings were used in all applications except for the attachment of the pneumatic valves to the tubing where we used swagelok fittings provided by the manufacturer. Appendix 3B details the vacuum line specifics as used in this system.

\section{SOFTWARE}

A complete listing of one MICROSOFT Fortran and four $C 4$ BASIC programs can be found in Appendix 5. Each program will be individually described below.

\subsection{Clear.bas}

Clear.bas is a C4 BASIC program which clears the existing storage area so that NOVOS can be used to reinitialize the system. Download the program and save it in an empty slot of the directory and run it. The program will ask the user to input the starting address of the storage area. If you are unsure what the storage address is, type NOVOS, and the address of the storage area will be printed on the screen. In the present configuration, input ' $\& 7400$ '. (Remember to enter the hex symbol ' $\&$ ' before the address number) The system will either lock up and you will have no keyboard control or 'Enter program number' will be printed. 
In either case, power the system down for 15 seconds and reset the button on the power supply card. Now the system is ready to be reconfigured following the procedure outlined in Appendix 6.

\subsection{Loader.bas}

Loader.bas is a $C$ \& $B A S I C$ program which loads into memory, two Z80 machine language subroutines which perform I/O operations not provided for in $C_{4} B A S I C$. The first, RDKEY, reads a single key stroke from the NEC console; returning the ASCII code of the key pressed via the $C \& B A S I C$ function USR(X). The second, METIO, reads a string of up to 16 characters from the METTLER digital balance through serial port B on the Z80 board, storing their ASCII codes in a buffer from which they may be read by means of the $C \& B A S I C$ function PEEK. Installing these two subroutines is complicated by the fact that $C_{4} B A S I C$ has no built in commands to store machine language routines in its file system or to load them into memory. Loader.bas was therefore written to use the $C \& B A S I C$ function, POKE, to poke them into memory one byte at a time starting at \&DC01. Although the subroutines are less than 100 bytes long, it was necessary to reserve a full $1 \mathrm{~K}$ of memory for the routines because that is the minimum that $C \& B A S I C$ configuration procedure allows. The system has already been configured to protect the addresses \&DC01-\&DCFF from $C \& B A S I C$. However, if the system is ever reconfigured, it is essential that these addresses be reserved.

\subsection{Getdata.bas}

Getdata.bas is a $C 4 B A S I C$ program used to make consequetive measurements of reaction time versus digital pressure on a single sample. It is useful for leak testing of the system as well as determining the necessary reaction time needed for the complete evolution of $\mathrm{CO}_{2}$ gas from a sample. Download the program into an empty directory location. Next load a sample boat into whichever load slot is to the right of the delivery slot, close the carousel, and run the program. The user will be asked to input the numbers of paired data to be collected ( 80 maximum). The user will next be asked to input the interval in seconds between measurments. 
Decide the time interval over which you want to collect data and plan the number of data points collected and seconds between each collection accordingly. At the program end hit $\langle\mathrm{P}\rangle$ to print the data to the screen or $\langle\mathrm{Q}\rangle$ to quit. If you wish to copy the data to a disk, you will need to use a screen capture program. We use $A S Y N C$ as described on page 11.

\subsection{Percent.for}

Percent.for is a MICROSOFT Fortran program which determines the percent carbonate for samples run on the Automated Carbonate System. At least two runs of $100 \%$ carbonate standards are first run to produce a regression line of slope and intercept for each batch of acid (see OPERATIONS, p. 14). The program can then be recompiled with the new slope and intercept data or interactively on the screen each time the program is used. The user will first be asked for the input filename. (By convention we always name the raw data from the carbonate system with 'filename.crb'). The slope and intercept will then be listed. If you wish to use the default values hit $\langle$ RET $>$, otherwise insert the values you wish to use. Finally, the user will be asked to name the output file. (By convention we always name the converted data file 'samefilename.pct'). The program will crash if 'samefilename.pct' already exists. If it does, simply delete it and rerun the program.

\subsection{Animat.bas}

Animat.bas is the C4 BASIC program which controls the Automated Carbonate System. The program is almost exculsively menu driven through two menus: (1) The Main Menu and (2) Tweak the System Menu. Each of the menus is detailed below including a few 'hidden' functions which may be called at any time. 


\subsubsection{The Main Menu}

The Main Menu

$\langle W\rangle$ to weigh the samples

$<\mathrm{L}>$ to load the sample boats

$<R>$ to run samples

$\langle$ P $\rangle$ to print the data

$\langle$ I $>$ to reinitialize

$<\mathrm{T}\rangle$ to tweak the system

$<Q>$ to quit

$<\mathrm{W}>$ to weigh the samples

This option is used to weigh out the samples into the sample boats and to enter their corresponding depth values. It has several 'hidden' functions which can be accessed through the use of control characters. Typing " " Z' at any prompt returns the user to the main menu. If the balance drifts after it has been tared, it can be retared by typing " $T$ ' at the 'Add the sample to the boat and hit any key when it is ready to be weighed $=>$ ' prompt. If the balance drifts after the sample has been weighed it can be reweighed by entering " $W$ ' at the 'Do you wish to redo this sample? ( $\mathrm{Y} / \mathrm{N})$ ' prompt. Occassionally the balance will refuse to tare or weigh on the first sample only. This problem seems to occur when the balance has been turned off or has been used between carbonate runs. Abort to the main menu by typing ' $A$ '. Turn the balance off and on several times and then reboot the system by running the Loader and Automated Carbonate System programs. Finally, reinitialize the memory.

\section{$<\mathrm{L}>$ to load samples}

This option prompts the user to load the sample boats one at a time into their proper holes in the lazy susan's carousel. The sample carousel must be correctly aligned at the beginning of the load sequence for proper system operation (see Appendix 7). If the lazy susan jams while loading or is at the wrong load slot:

1. Exit to the main menu by typing " $\mathrm{Z}$ '

2. Call up the 'Tweak the system menu' by typing ' $\mathrm{T}$ '

3. Select the 'Home the lazy susan' option by typing ' $H$ ' 
4. Home the lazy susan so that the hole with the same number as the next sample you wish to load in in the load slot position. (see Appendix 7)

5. Exit to the 'Tweak the system menu' by typing ' $E$ '

6. Exit to the main menu by typing ' $E$ '

7. Reenter the Load option by typing ' $L$ ' An error message will be printed and this option will refuse to execute if (a) all 40 samples have not been weighed out before it is called or (b) the samples have already been run.

\section{$<\mathrm{R}>$ to mun the samples}

This option reacts the individual samples and stores the pressure values in the systems internal file structure so that they may be uploaded using the ' $<\mathrm{P}\rangle$ print the data' option at the end of each run. The user is prompted to select one of two reaction times for analysis of individual samples based on the expected carbonate content. If the lazy susan jams while the 'Run the samples' option is executing, an error message will appear on the screen.

1. Hit the Escape key, '<Esc>'. This breaks the Animating Element. A system prompt, '*', should appear.

2. Type 'run 1' to reexecute the ACS program. The prompt 'Skip software initialization? $(\mathrm{Y} / \mathrm{N})$ ', should appear.

3. Type ' $Y$ ' to skip the initialization. This preserves the systems internal file structure.

4. Type ' $N$ ' at the 'Is the lazy susan homed to slot \#1? (Y/N)', prompt. The Homer menu will be displayed.

5. Home the lazy susan to correct the jam, preserving the jammed sample if possible.

6. Exit to the 'Tweak the system...' menu by typing ' $E$ '. '

7. At the prompt, enter the number of the hole in the carousel which is over the load slot, not the number of the next sample to be run. (see Appendix 7)

8. Type ' $R$ ' at the 'Tweak the system...' menu to resume running.

Do not run any other program or call NOVOS between the time you break the program 
by typing 'Esc' and the time you reexecute the ACS program. The data in the system's file structure (i.e. the weights of all the samples and the pressure values of the samples which have already been run) will be destroyed. The ' $R$ ' option will not execute until all the samples have been weighed and loaded.

$<\mathrm{P}>$ print the data

This option is used to print out the system's data file so that it may be uploaded to a floppy disk using $A S Y N C$ 's 'Get a file' function.

1. After the 40 samples has been been run and the main menu is listed, type " VF' to call $A S Y N C$ 's 'Specify file name for transfer' function. The $A S Y N C$ prompt 'File specification:' will appear.

2. Enter the drive and filename the data is to be saved under and hit '<return>'.

3. Type " VG' to call $A S Y N C$ 's 'Get a file' function. The message 'Port-> filename/File open, rdy to rcv' will appear on the top left corner of the screen.

4. Type ' $P$ '. The data will scroll on the terminal one line at a time.

5. When all 40 lines of data have been printed on the terminal screen, type " $Z$ '. This closes the file and the message ' ++ File received ++ ' will appear after the main menu is printed.

\section{$<\mathrm{I}>$ to reinitialize}

This option is used to reinitialize the system so that another batch of 40 samples can be run. The execution of this option destroys all the data in memory.

\section{$<\mathbf{Q}>$ to quit}

This option is used to exit the ACS program and enter C4 BASIC. Do not execute this option unless the data has been already uploaded. It is almost always possible to reenter the ACS program program without destroying the data by typing ' $Y$ ' at the 'Skip software initialization? (Y/N)' prompt, but it is not worth the risk. If you must, see steps \#2 and \#3 for unjamming under the 'Run the samples' option. 


\subsubsection{Tweak the System Menu}

Tweak the System Menu

$<A\rangle$ for atmosphere

$\langle\mathrm{V}\rangle$ for vacuum

$\langle\mathrm{W}\rangle$ to reweigh a sample

$<\mathrm{R}>$ to continue after a jam up

$\langle\mathrm{C}\rangle$ to check the pressure in the vessel

$\langle E>$ to exit to the main menu

$<H>$ to home the lazy susan

\section{$<\mathrm{A}>$ for atmosphere}

This option opens the vessel to the atmosphere by closing the valve to the pump and opening the valve to the atmosphere.

\section{$\langle\mathrm{V}\rangle$ for vacuum}

This option pumps the reaction vessel down by closing the valve to the atmosphere and opening the valve to the pump.

\section{$<\mathrm{W}>$ to reweigh a sample}

This option allows the user to reweigh a sample after all samples have been weighed. The user will be prompted for the number of the sample to be reweighed and then the normal weighing protocol is followed.

\section{$<\mathrm{R}>$ to continue after a jam up}

This option is used to continue running after the normal 'run samples' has been interrupted. Do not call this option until the lazy susan has been homed so that the carousel will drop the next desired sample into the reaction vessel. See the 'Home the lazy susan' menu above.

$<\mathrm{C}>$ to check the pressure in the vessel

This function allows the user to leak test the vessel over a selected period of time. The option closes both valves so remember to reopen the valve to the pump if you want to continue pumping on the acid after checking the pressure. An error message will be printed if this option is executed while the vessel is open to the atmosphere. 


\section{$<\mathrm{E}>$ to exit to the main menu}

This option returns the user to the main menu.

$<\mathrm{H}>$ to home the lazy susan

This option calls up another menu of functions which are used to home the lazy susan.

\subsubsection{Homer Menu}

$$
\begin{aligned}
& \text { Homer Menu } \\
& \text { <Right arrow }>=\text { counter-clockwise } \\
& \text { <Left arrow }>=\text { clockwise } \\
& \text { <Up arrow }>=\text { continuous step mode } \\
& \text { <Down arrow }>=\text { single step mode } \\
& <\text { S }>\text { Smart Home Option } \\
& <\text { E }>\text { = Exit }
\end{aligned}
$$

This menu allows the user to manipulate the lazy susan's carousel from the keyboard. The '<Right arrow>' and '<Left arrow >' keys control the direction of rotation of the lazy susan. The '<Up arrow' $>$ ' and '<Down arrow $>$ ' keys switch between single step mode and continuous step mode. In single step mode, the lazy susan moves a single step in the direction of the pressed direction key. In continuous step mode, the lazy susan moves in the direction of the last pressed direction key. Pressing any key except for '<Up arrow >', '<Right arrow >' or '<Left arrow >' will cause the lazy susan to stop in continuous step mode. The carousel must be aligned to load slot \#1 at the beginning of the load sequence (see Appendix 7).

\section{<S S Smart Home Option}

The smart home option asks the user for the number of the hole positioned over the load slot and automatically homes the lazy susan to load slot number 1 . In order to use the smart home option, you must first use the the arrow keys to home the lazy susan to the nearest load slot. Do not use this option if the boats have already been loaded into 
the lazy susan. This option chooses the direction of rotation based upon the shortest distance to the load slot and may dump loaded boats into the acid in the process of homing the carousel.

$<\mathrm{E}>$ Exit

This option prompts the user to enter the load slot which the lazy susan has been homed to and then returns to the 'Tweak the system...' menu. This program has no encoding mechanism and thus has no way of knowing where the carousel is other than asking the user. The program does not know which load slots have boats in them and cannot keep you from dumping boats into the acid by accident!!

\section{OPERATIONS}

Once the hardware and software have been installed and are functioning correctly, the phosphoric acid and reaction vessel can be calibrated by running at least two standard runs of $100 \%$ calcium carbonate. Data from two carbonate standard runs are shown in Figure 2. The slope and intercept of the regression line produced from such standard runs are used in percent.for, the fortran program which converts raw data produced on the ACS to percent carbonate data.

We have found that a constant volume of acid delivered to the reaction vessel is critical to produce consistent, accurate results. Room temperature $100 \%$ phosphoric acid is quite viscous. We found that the repipette manufactured by LABINDUSTRIES $C$ consistently delivers accurate volumes. (A complete listing of components for the ACS can be found in Appendix 8). We adjust the $20 \mathrm{ml}$ repipet to deliver two $10 \mathrm{ml}$ aliquots of acid because in the process of drawing up $20 \mathrm{ml}$, bubbles always form at the pipette tip causing inaccurate volumes. A glass-covered spin bar is added to the acid-filled reaction vessel. The reaction vessel should now be attached to the carousel assembly, heated to $80^{\circ} \mathrm{C}$, and put under vacuum to begin the outgassing process. Under atmospheric conditions, the microvoltmeter 
should read an over-pressure voltage of \pm 13 . Once pumpdown begins, the voltage will quickly drop to below 1 volt if no leaks are present. Within 2 minutes of pumping under vigorous spinning action, the voltage should drop below 0.10 volts. The user is ready to weigh out the $100 \%$ dried reagent grade calcium carbonate standard samples into the sample boats (see Appendix 3D for sample boat specifications).

The first boat to be weighed should be listed as 'sample 1'. If the first sample listed is 'sample 0', exit the weighing procedure and reinitialize the buffer memory by hitting the <I> under 'The Main Menu'. Then proceed with the weighing process. When producing a standard carbonate run, weigh out a range of weights from $1 \mathrm{mg}$ to $20 \mathrm{mg}$. The first sample should always be large, to fully saturate the acid with $\mathrm{CO}_{2}$ (the percent carbonate value of the first sample is always $10-15 \%$ low and is deleted). Once all 40 boats have been filled, use a finnpipette to deliver $5 \mu 1$ of reagent grade methanol to each sample boat. We have found that on the initial pumpdown from atmosphere to vacuum, material can be lost from the boats nearest the reaction vessel delivery slot (boats 35-5). When dried, the methanol produces a thin crust which adheres the sediment particles together. Place the 40 boats into an oven to dry. The samples are dry when they are no longer shiny (5-10 minutes at $\left.60^{\circ} \mathrm{C}\right)$. The boats can now be loaded into the sample carousel, if load slot 1 is in the correct position (see Appendix 7).

Once the ULTRA-TORR fitting on the carousel assembly is secure, the system is ready to run. A choice of two reaction times will appear on the screen. We have found that our initial 5 minute reaction time was not long enough to fully evolve the $\mathrm{CO}_{2}$ from sediment samples having low carbonate contents. To determine the optimal reaction time for sediments of varying carbonate content, we conducted an experiment using Getdata.bas. The results of this experiment are shown in Figure 3. In general, the evolution of carbonate to $\mathrm{CO}_{2}$ gas is complete within one minute. However, in samples with less than $25 \%$ carbonate content, it is apparent that a much longer reaction time is necessary. Data collected from a second experiment on samples with less than $40 \%$ carbonate over a 45 minute reaction time are shown in Figure 4. These results show that a 20 minute reaction time is necessary for sediment samples with less than $25 \%$ carbonate. A small but gradual increase in percent 
carbonate after 20 minutes is water vapor outgassing from the acid. The precision of replicate analyses of samples run on the ACS with high, medium and low concentrations of carbonate vary between $0.49 \%$ and $0.88 \%$ as shown in Figure 5 .

As the run begins, the valve to the pump opens and the pressure in the system quickly drops to .12 volts (which corresponds to 0.04 torr) and the pump valve closes. A 'stable pressure' algorithm collects a pressure value every six seconds and waits for ten consecutive values which do not change by more than .01 volts. For the first few samples it may take the computer longer than a minute to accept a background stable pressure value. By the fifth sample, however, only one minute is necessary before a stable background pressure value is reached and the next sample boat is dropped into the acid. Based upon the reaction time chosen, the system will wait for that amount of time before beginning the 'stable pressure' algorithm to collect the final pressure value. The initial background pressure is subtracted from the final stable pressure to produce the digital pressure listed in the data table.

If a sample happens to be reacting at the end of the chosen reaction time, the system will wait for the reaction to be complete before a stable pressure value is accepted and the next sample is dropped. If there is a leak in the system the pressure will never stabalize and the run will not continue. When leak is so bad that atmospheric pressure is reached, an error message will appear on the screen and the run will be terminated.

At the end of each run, the main menu will be printed on the screen. We recommend that the data from each complete run be uploaded onto a floppy disk as soon as possible. At present, the system has no battery backup protection and when the power fails, the data is lost. You can expect a typical 'high carbonate' run to take 4.5 hours while a 'low carbonate' run will take at least 14.5 hours. For this reason we run high carbonate samples during the day and the low carbonate samples overnight for maximum data output. Do not increase the sample weights of low carbonate samples in order to produce a greater pressure signal. The clays in low carbonate samples will turn the acid into a thick mass making the run invalid. We keep the sediment sample weight in each boat within the range of 15 to $20 \mathrm{mg}$ of material for best results. If problems are encountered, refer to the "Trouble Shooting guide in Appendix 9. For a condensed 'System Startup' procedure, see Appendix 10. 


\section{REFERENCES}

Coplen, T. B., Kendall, C., and Hopple, J., 1983, Comparison of stable isotopic reference samples: Nature, v. 302, p. 236-238.

Curry, W.B., and Lohmann, G.P., 1985, Carbon deposition rates and deep water residence time in the equatorial Atlantic Ocean throughout the last 160,000 years, in Sundquist, $\mathrm{E}$. T., and W. S. Broecker, eds., The carbonate cycle and atmospheric $\mathrm{CO}_{2}$ : natural variations, Archean to present: American Geophysical Union Monograph 32, p. 285-301.

\section{Acknowledgements}

We would like to thank E. Franks, C. Goyet, L. Keigwin, K. Miller, D. Oppo and N. Slowey for helpful criticisms of the many drafts of this manual. We credit V. Asper for his initial inspiration and technical support as we began development of the carbonate system. We also thank P. Oberlander of the W.H.O.I. Graphics Department for his beautiful illustrations of the carbonate system and it's associated parts. The development of the carbonate system was supported by NSF grants OCE85-11014 (W. B. Curry) and OCE88-13307 (W. B. Curry). 
Figure 1. Automated Carbonate System Schematic.

A. 28 volt DC power supply (for stepping motor \& valve solenoids)

B. Card cage including the following boards:

1. power supply ( $5 \& 12$ volt $\mathrm{DC}$ )

2. Z80 computer

3. Analog input

4. Memory expansion

5. Dual stepper controller

6. Relay output

C. Microvoltmeter (to display transducer pressure)

D. 15 volt DC power supply (for pressure transducer)

E. Pressure transducer

F. Pneumatic valves with attached solenoid actuator

G. Stepping motor

H. Lazy susan sample carousel

I. Water jacketed reaction vessel

J. Spin bar mixer

K. Unipolar stepper driver

L. Vacuum pump oil trap 
Figure 1. Automated Carbonate System Schematic.

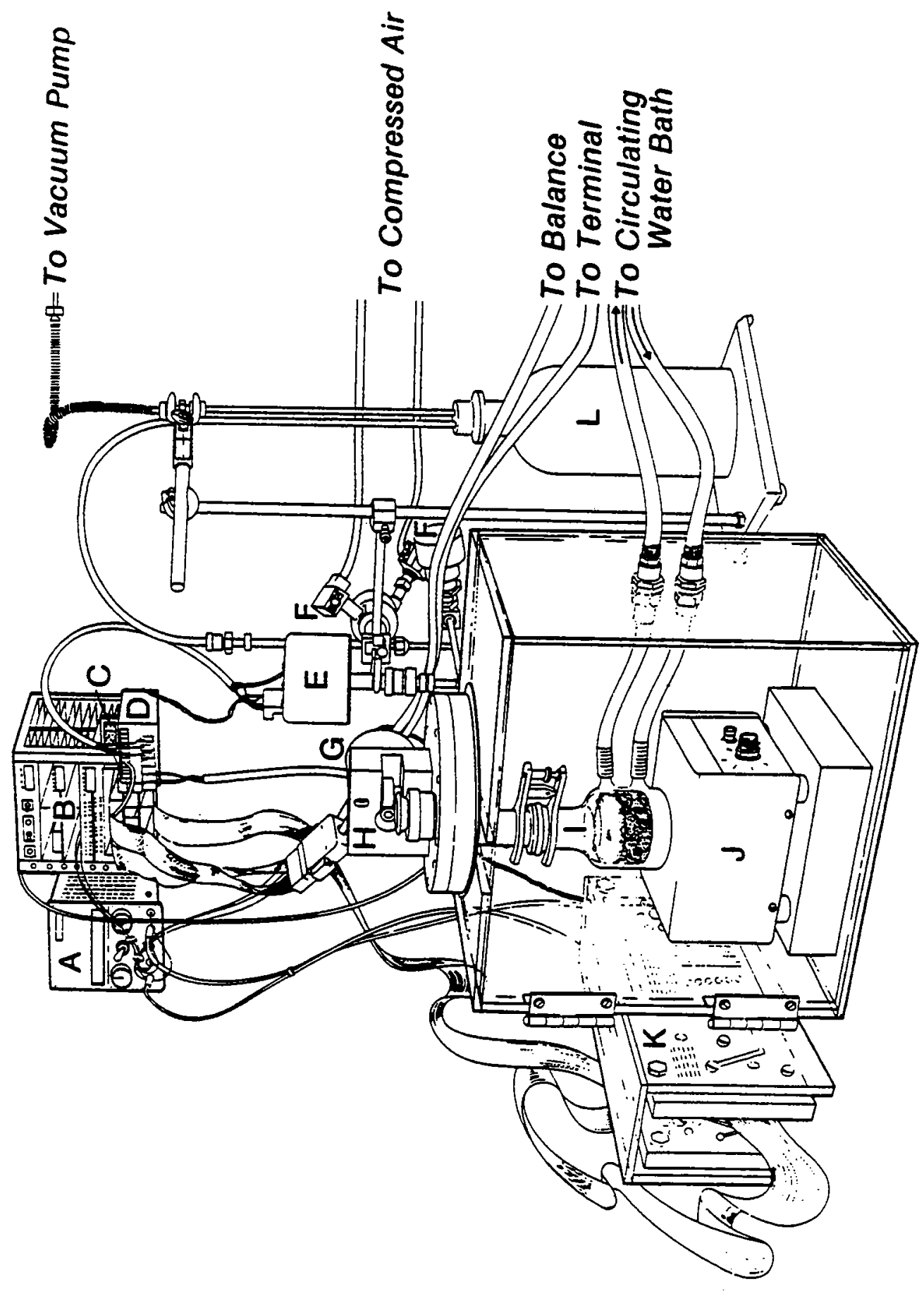




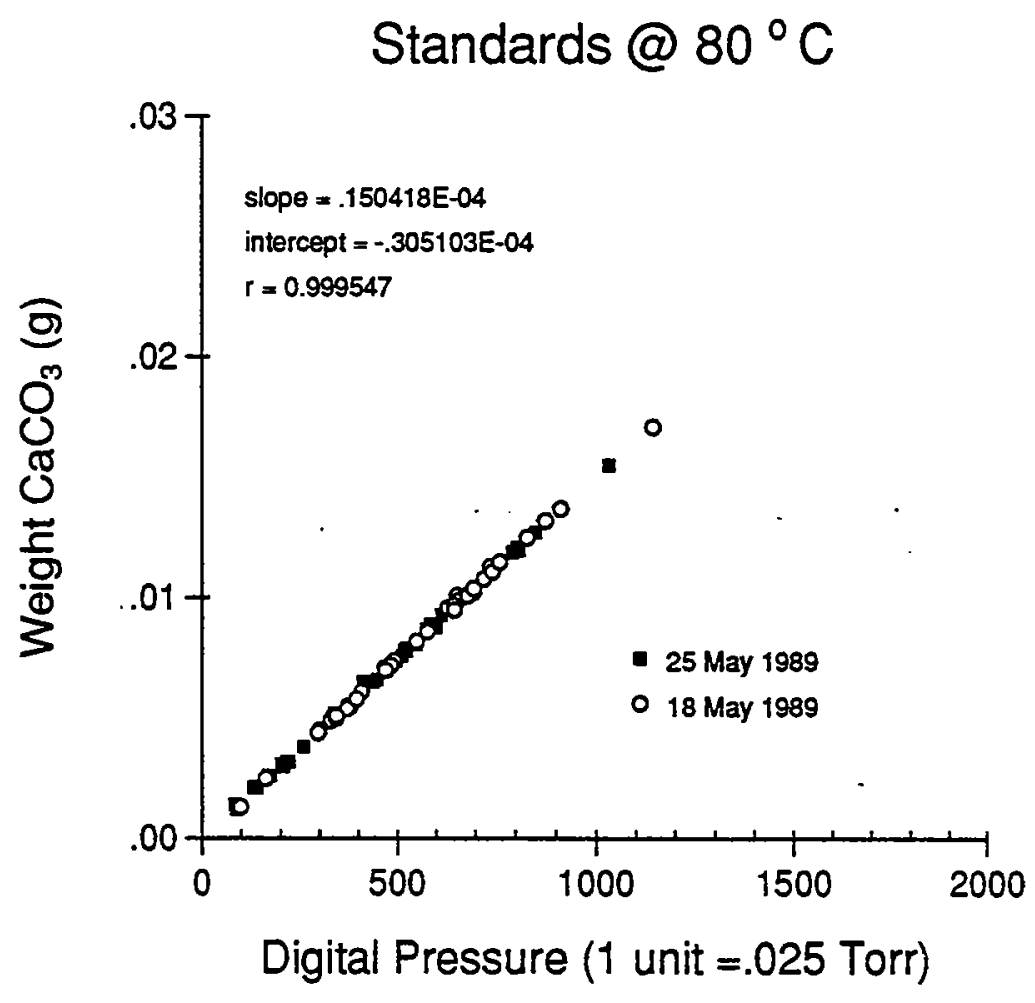

Figure 2: Two runs of $100 \%$ reagent grade calcium carbonate standards. The slope and intercept of the regression line produced from standards are used to calculate percent carbonate in unknown samples. For each new batch of phosphoric acid used, a new regression line is produced from standard runs. 


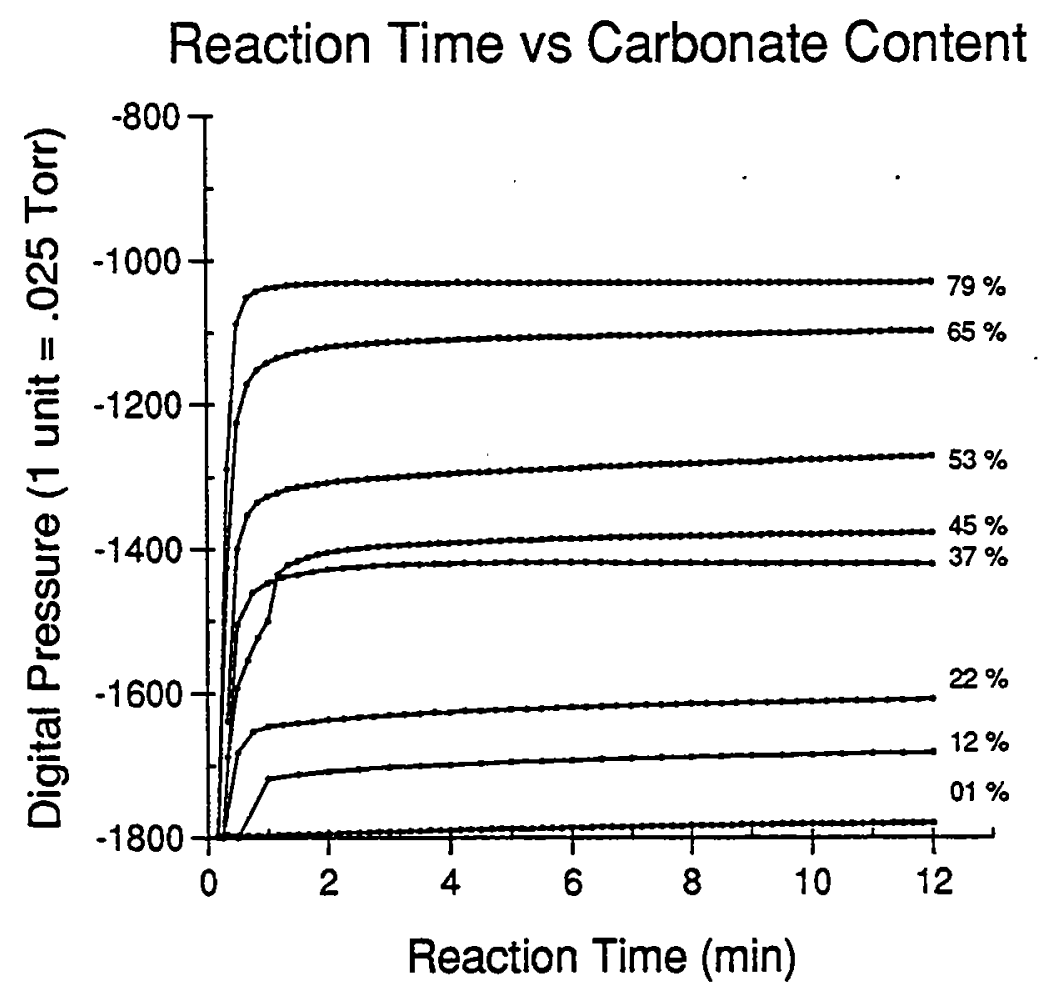

Figure 3: Reaction time for samples of varying carbonate content. For all samples, the bulk react of sample to $\mathrm{CO}_{2}$ is complete within one minute. However, samples with less than $37 \%$ carbonte continue to react even after 12 minutes. The sediments are from cores recovered from the Sierra Leone Rise in the eastern equatorial Atlantic (Curry and Lohmann, 1985). 


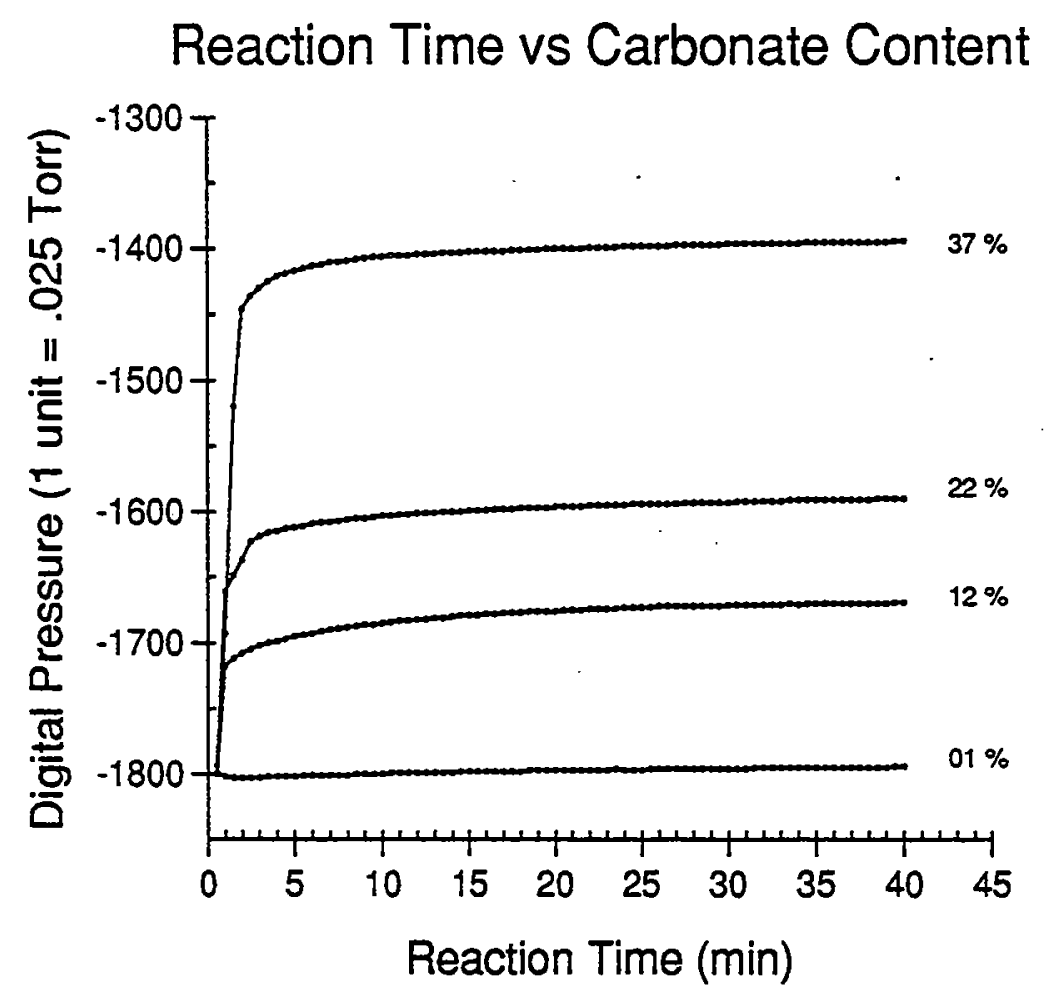

Figure 4: Reaction time for samples of low carbonate content. These samples were allowed to react for 40 minutes to find the reactime needed to evolve all the $\mathrm{CO}_{2}$ from low carbonate samples. At 20 minutes, the reaction is complete and is $98-100 \%$ of the $\mathrm{CO}_{2}$ value after 40 minutes. We believe that the small but gradual increase in carbonate content after 20 minutes is due to water vapor accumulation from acid outgassing. The sediments are from cores recovered from the Sierra Leone Rise in the eastern equatorial Atlantic (Curry and Lohmann, 1985). 
Sample Precision

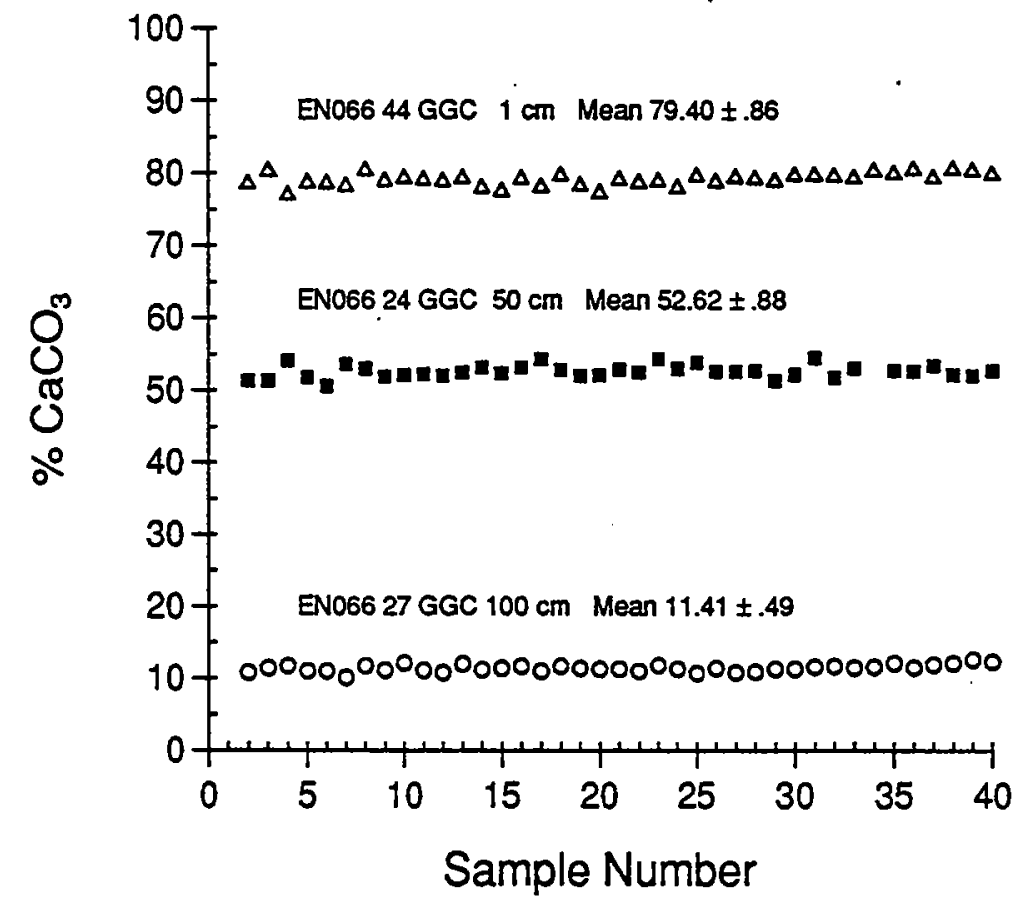

Figure 5: Sample precision versus carbonate content. We show 120 replicate analysis of carbonate for samples with high, medium and low concentrations. The sediments are from cores recovered from the Sierra Leone Rise in the eastern equatorial Atlantic (Curry and Lohmann, 1985). 
Appendix 1. Board jumpering specifics.

Board Jumpering - Various options are available on each of the following boards and are selected using removable jumper plugs. Features are selected by installing or removing the jumper plugs as noted below. See the appropriate manuals for further explanation. Only jumpers which are to be installed are detailed unless specifically noted.

\section{VL-7806 (Z80 CPU)}

J4 Memory map select/segment signal connector

M0 thru M3 use 8K Eprom chips

V1 a - connects CTC output 1 to serial channel B baud input

V1 c - connects SYSCLK/2 to CTC input 1

V2 DCE to terminal

V3 DCE to terminal

V4 DCE to terminal

V5 DTE to computer

V6 DCE to terminal

V7 DTE to computer

V8 DTE to computer

V9 DTE to computer

V10 b \& c - sockets M0-M3 are 8K RAM chips

V11 a, b, c, \& d - sockets M0-M3 are all enabled

V12 b - MEMEX is set low at power up

V13 MEMEX signal is controlled on the board

V14 a - IOEXP is connected to ground

V14 b - AUXGND is connected to digital ground

\section{DSC-7911 (Dual stepper controller)}

$\mathrm{J} 1$ no jumper - no interrupt desired

J2 center pin to NE, non-expanded I/O map

J7 E1 tied to 5 , clock frequency of $6.25 \mathrm{kHz}$

SW1 1-5 on, to be address 15 matching A3-A7

SW1 6 off, enables the card 
Appendix 1. Board jumpering specifics continued.

VL-7709 (64/256K memory board)
A $\quad$ M0 \& $\mathrm{M} 1$ are $8 \mathrm{~K}$ chips and are disabled
B $\quad$ M2 \& $\mathrm{M} 3$ are $8 \mathrm{~K}$ chips and are disabled
C M4 \& M5 are 8K chips and M4 is enabled, M5 is disabled
D $\quad$ M6 \& $\mathrm{M} 7$ are $8 \mathrm{~K}$ chips and are disabled
V2 a-f all installed for no bank switching
V3 c, e, \& $\mathrm{g}-8 \mathrm{~K}$ chips used for a total of $64 \mathrm{~K}$
V4 d \& $\mathrm{h}$ - bank control port address EE
V5 b - IOEXP is active low
V6 no jümpers installed - 16 bit addressing without bank control

\section{VL-STD AIN-1 (integrating analog input board)}

$7 \quad=$ address of the board

$\mathrm{d}=$ differential input mode selected

\section{USD-7911 (Unipolar stepper driver)}

E1 voltage range 8 - 32 volts

E2 external 5 volt supply not allowed

H3 Motor connections used

H3 pin 3 phase 4 output

H3 pin 4 phase 3 output

H3 pin 5 phase 2 output

H3 pin 6 phase 1 output

H3 pin 9 phase 1 common

H3 pin 11 motor supply voltage ground

H3 pin 12 motor supply voltage $(+)$ 
Appendix 2. Automated carbonate system memory map.

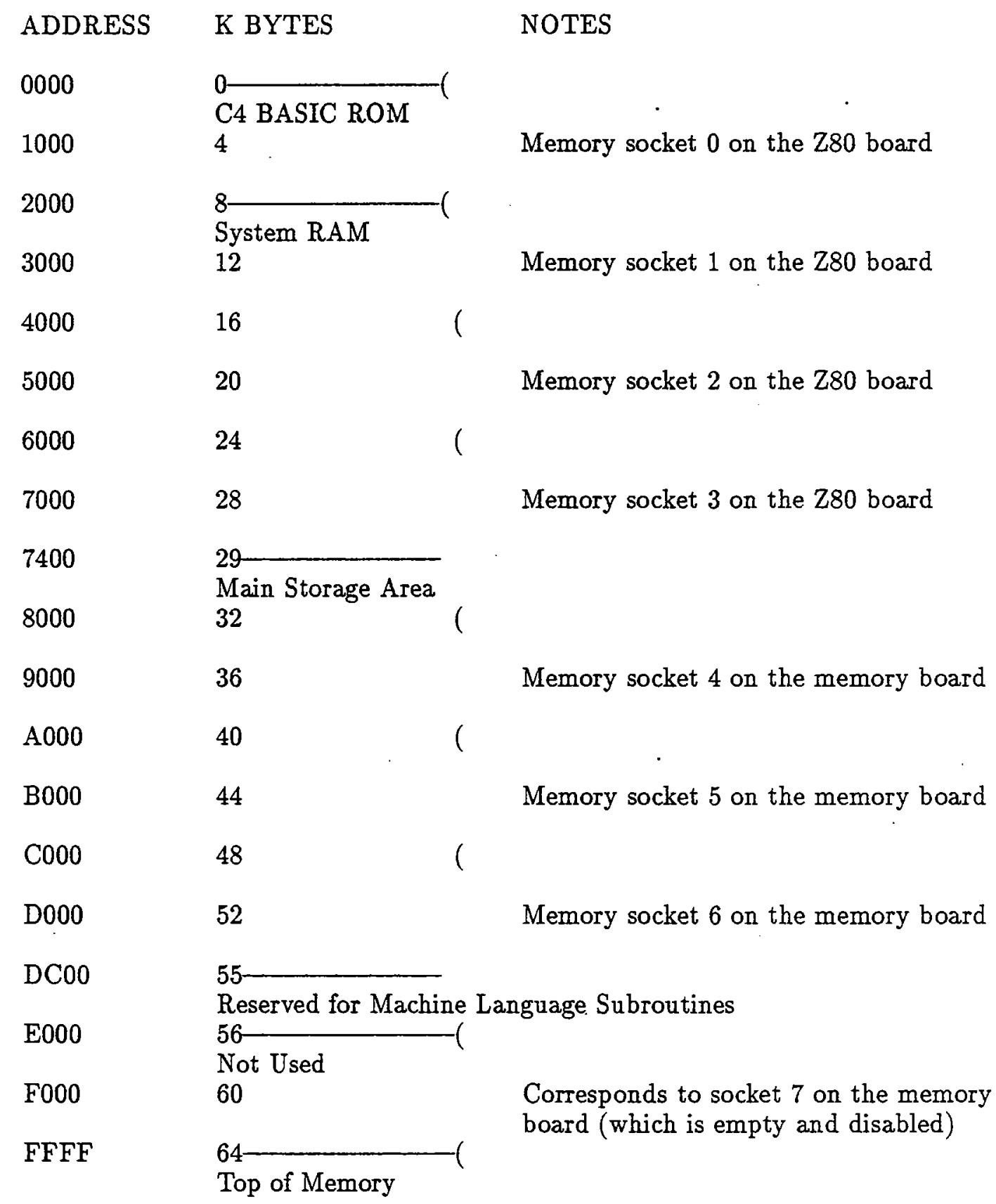


Appendix 3. System component diagrams.

A Connecting the transducer

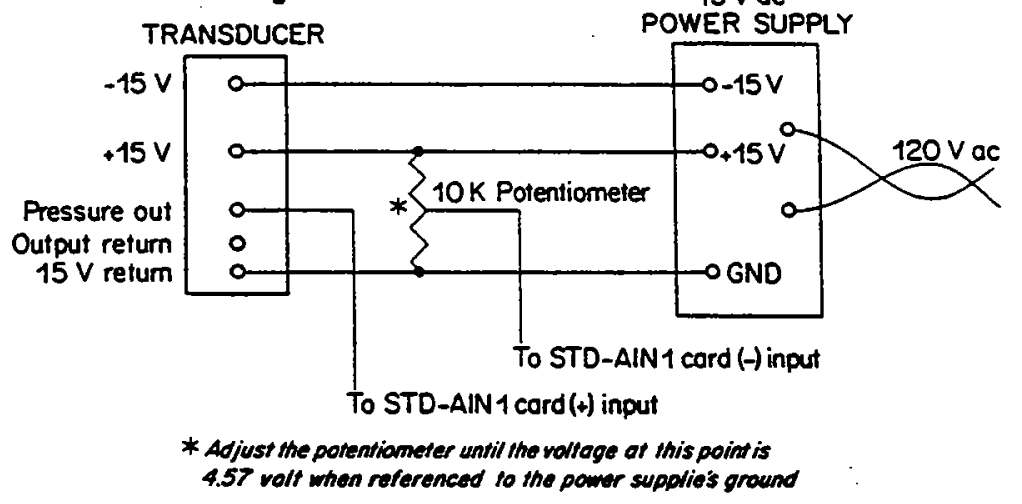

B Carousel tubing assembly

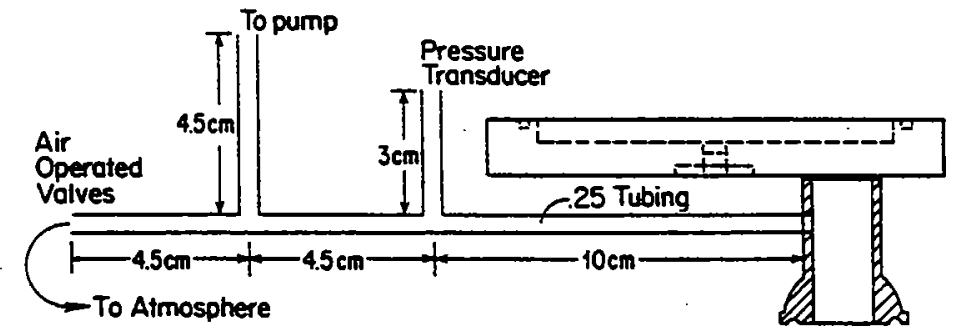

C Water jacketed reaction vessel

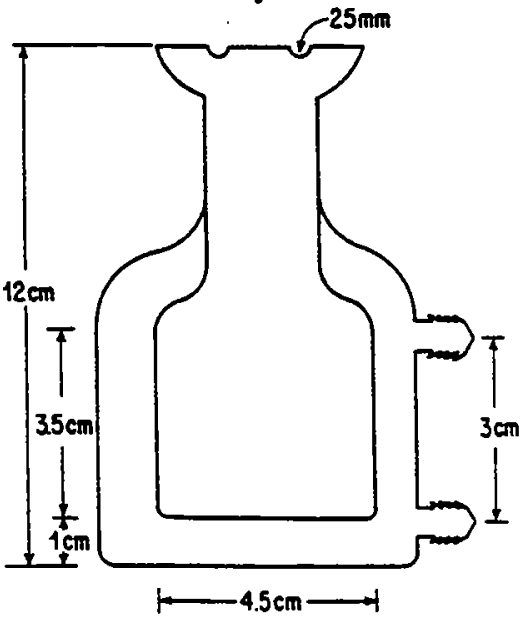

D Boat Specifications $.25^{\prime \prime}$ copper rod stock used

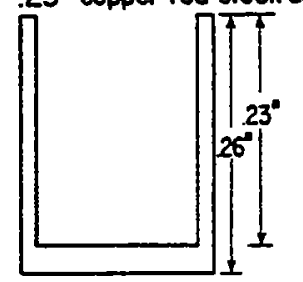


Appendix 4. Phosphoric acid mixing procedure.

This procedure is modified from Coplen et al, 1983 and is the same procedure used in the WHOI mass spectrometer facility. The $200^{\circ} \mathrm{C}$ hot acid will remove the ink from the thermometer so the thermometer should be inserted into a glass tube sealed at one end before immersing into the acid. Once the acid has cooled, it can be stored in a glass bottle with a cap containing a conical insert for tight sealing.

Chemicals needed:

$\mathrm{P}_{2} \mathrm{O}_{5} \quad$ Phosphorus pentoxide $(2.01 \mathrm{~kg})$

$\mathrm{H}_{3} \mathrm{PO}_{4}$ Phosphoric acid (4.30 kg or 2.5 liters $85 \%$ )

$\mathrm{CrO}_{3} \quad$ Chromium (ic) oxide (10 mg)

$\mathrm{H}_{2} \mathrm{O}_{2} \quad$ Hydrogen peroxide $(3 \mathrm{ml} 50 \%)$

Procedure:

1. Place a 4 liter beaker on a hot plate in a fume hood, wrapping the beaker in aluminum foil. The foil will help the acid maintain a constant temperature while the fume hood is operating.

2. Mix together the phosphorus pentoxide, the phosphoric acid and the chromium oxide. The solution should be yellow.

3. Heat uncovered at $200^{\circ} \mathrm{C}$ for 7 hours.

4. Add the hydrogen peroxide.

5. Heat uncovered at $220^{\circ} \mathrm{C}$ for 4.5 hours. The original 3.5 liters will evaporate to 3.25 liters.

6. The specific gravity of the final solution should be between 1.90-1.92. If it is not, more phosphorus pentoxide should be added as required and the entire process is repeated from step 3. 


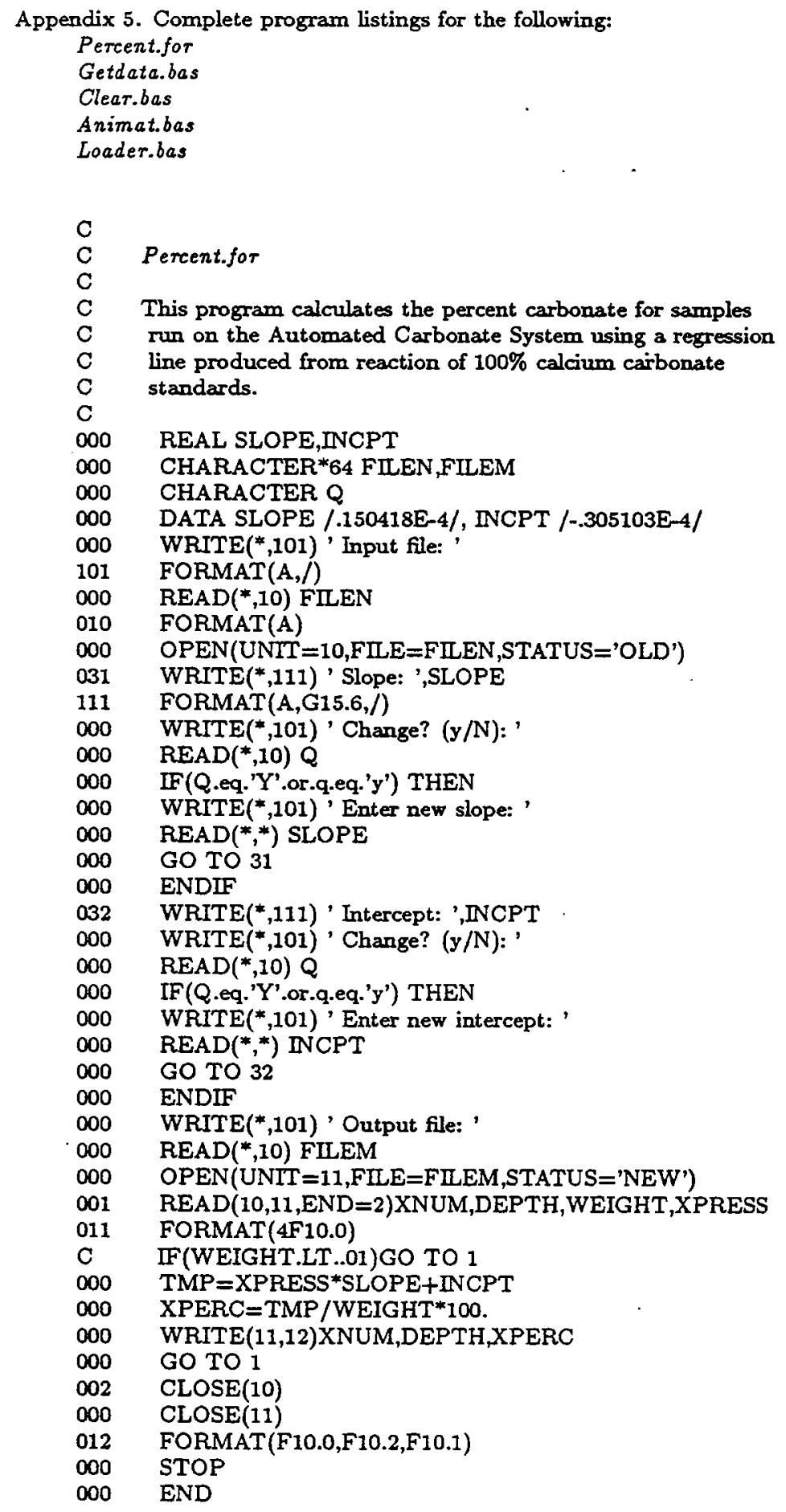




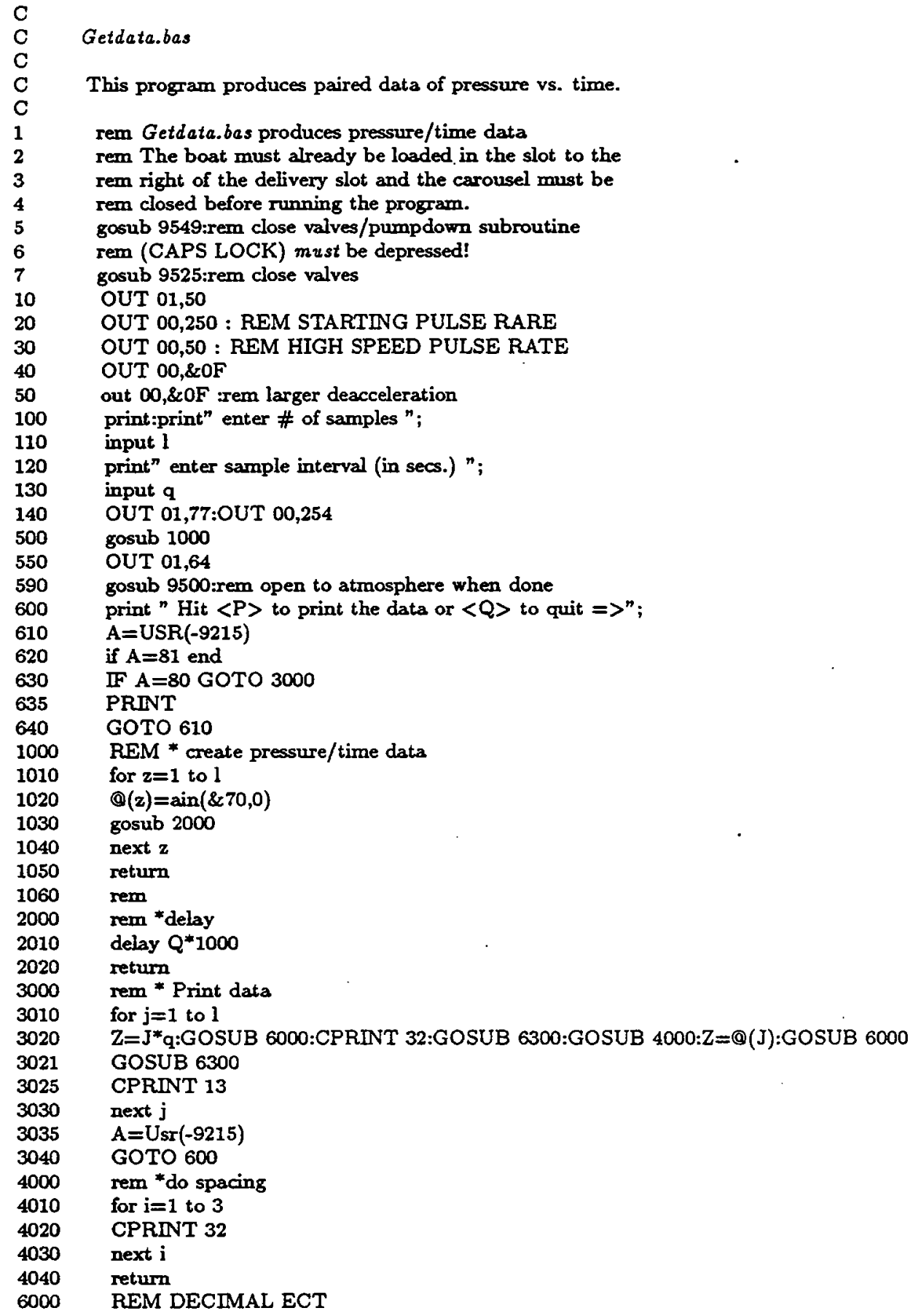

This program produces paired data of pressure vs. time.

rem Getdata.bas produces pressure/time data

rem The boat must already be loaded in the slot to the rem right of the delivery slot and the carousel must be rem closed before running the program.

gosub 9549:rem close valves/pumpdown subroutine

rem (CAPS LOCK) must be depressed!

gosub 9525:rem close valves

OUT 01,50

OUT 00,250 : REM STARTING PULSE RARE

OUT 00,50 : REM HIGH SPEED PULSE RATE

OUT $00, \&$ \&OF

out $00, \& 0 F$ :rem larger deacceleration

print:print" enter \# of samples ";

input 1

print" enter sample interval (in secs.) ";

input $q$

OUT $01,77:$ OUT 00,254

gosub 1000

OUT 01,64

gosub 9500:rem open to atmosphere when done

print " Hit $\langle P\rangle$ to print the data or $\langle Q\rangle$ to quit =>";

$A=U S R(-9215)$

if $A=81$ end

IF $A=80$ GOTO 3000

PRINT

GOTO 610

REM * create pressure/time data

for $z=1$ to 1

@(z)=ain $(\& 70,0)$

gosub 2000

next 2

return

rem

rem * delay

delay $Q^{*} 1000$

return

rem * Print data

for $j=1$ to $l$

$\mathrm{Z}=\mathrm{J}$ *q:GOSUB 6000:CPRINT 32:GOSUB 6300:GOSUB 4000:Z=@(J):GOSUB 6000 GOSUB 6300

CPRINT 13

next $j$

$A=U s r(-9215)$

GOTO 600

rem *do spacing

for $i=1$ to 3

CPRINT 32

next $i$

return

REM DECIMAL ECT 
Getdata.bas continued.

6005

6010

6015

6020

6050

6055

6060

6065

6070

6075

6100

6110

6120

6130

6140

6190

6200

6210

6215

6220

6230

6240

6300

6305

6310

6330

6340

6350

9549

9500

9501

9525

9526

9550

9551

REM This routine takes the var. $Z$ and creats a

REM 5 byte string of \#'s ,containing the the ASCII codes for the

REM characters which make up the printed representation of the \# $Z$

REM and stores them in $\mathrm{D}(0)-\mathrm{D}(4)$

FOR X $=0$ TO 5:D(X)=32:NEXT X

$\mathrm{D}(1)=48$

$C=2: P=10000$

REM if $Z$ is negitive then $D(0)=45$ (45=the ASCII code for "-")

IF $A B S(Z)<>Z D(0)=45: Z=A B S(Z)$

IF $Z>9999 \mathrm{D}(1)=49: \mathrm{Z}=\mathrm{Z}-10000$

$\mathrm{D}(\mathrm{C})=\mathrm{MOD}(\mathrm{Z}, \mathrm{P}) /(\mathrm{P} / 10)+\& 30$

IF $\mathrm{P}=10 \mathrm{GOTO} 6200$

$P=P / 10$

$\mathrm{C}=\mathrm{C}+1$

GOTO 6100

REM remove leading 0 's and replace them with spaces

FOR $X=1$ TO 4

IF $\mathrm{D}(\mathrm{X})<>48$ RETURN

REM move sign 1 location to the right

$D(X)=D(X-1): D(X-1)=32$

NEXT $X$

RETURN

REM output contents of $\mathrm{D}(0)-\mathrm{D}(4)$ to dart channel $A$

$\mathrm{D}(6)=46: \mathrm{D}(7)=48$

FOR $X=0$ TO 7

CPRINT D(X)

NEXT X

RETURN

print:print "Pumping on the acid for 27 minutes";

rout $96,7,1$ :rem open to atmosphere at end

return

rout $96,6,0$ :delay 1000 :rem close valve to pump

return

rout $96,7,0$ :rout $96,6,1$ :delay 9000:delay 9000:delay 9000 :

rem 9550 close valves/pumpdown on acid for 27 seconds

Clear.bas

This program clears the existing memory configuration so that

the storage area can be reinitialized.

rem Clear.bas, last revised 26.8.89 (DRO)

rem this program nukes the existing storage area so that NOVOS can be rem re-initialized

rem CAUTION: this program destroys everything in the existing storage area rem NOTE: after you run this the computer will lock up. Type ' $O$ ' over and rem over until it comes back to life (see page 2-6 of the C4-BASIC manual) print " Enter the starting address of the storage area in hex "; rem As presently configured, input ' $\& 7400$ '

imput $h$

print " KABOOM !!!!!!!!! HA HA HA HA !!!!!"

for $z=0$ to 50 :poke $h+z, 0$ :next $z$ 


\section{Animat.bas}

This program runs the Automated Carbonate System.

rem The Animating Element, last revised 30.8.89 (DRO)

print:print" Welcome stranger." :print

rem hardware initialization

gosub 6800xem initialize serial port B to talk to the Mettler

gosub 7300:rem initialize motor controller card

print" Skip software initialization? (Y/N)";

gosub 700

rem if " $Y$ " then skip it

if $\mathrm{a}=89$ goto 91

print:print " Initializing......"

rem init. variables

for $z=0$ to 816:@(z)=32:next zxem clear out array

rem put zeros in the pressure value slots

for $w=1$ to $40: v 2=0$ :gosub 9310:next $w$

$\mathrm{N}=1$ :rem sample \# of the next sample $2 \mathrm{~b}$ weighed

$\mathrm{L}=40$ rem \# of boats

for $z=0$ to $7: f(z)=0$ :next $z$ zem zero all the flags

$12=5$ rem minimum pressure value (used in run routine)

print:print" Is the Lazy Susan homed to slot \#1 ? (Y/N)";

rem call up Homer menu if " $Y$ "

gosub 700:if $a=78$ gosub 5100:goto 100

$c=1$

print:print" The Animating Element"

print:print

print" Type :"

print" $\langle W\rangle$ to weigh samples"

print" $<L>$ to load the sample boats"

print" $\langle R>$ to run samples"

print" $<$ P $>$ to print the datan

print" $<$ I $>$ to re-initializen

print" $\langle\mathrm{T}>$ to tweak the system"

print" $<Q>$ to quit"

print:print:print

print" $=>"$;

gosub 700:rem call a ML single char input sub.( $A=$ the ASCII val of char) rem ASCII codes:87=" $A^{n}, 76=" L^{n}, 82=" R^{n}, 80=" P^{n}, 73=" I^{n}, 84=" T^{n}, 81=" Q "$ rem weigh samples

if $a=87$ gosub 1000:goto 110

rem load boats

if $a=76$ gosub 2000:goto 110

rem run samples

if $a=82$ gosub 3000:goto 110

rem print data

if $a=80$ gosub 4000 :goto 110

rem re-initialize

if $a=73$ goto 5000

rem call up system tweak menu

if $a=84$ gosub 500:goto 110

rem quit

if $\mathrm{a}=81$ goto 300

goto 190 


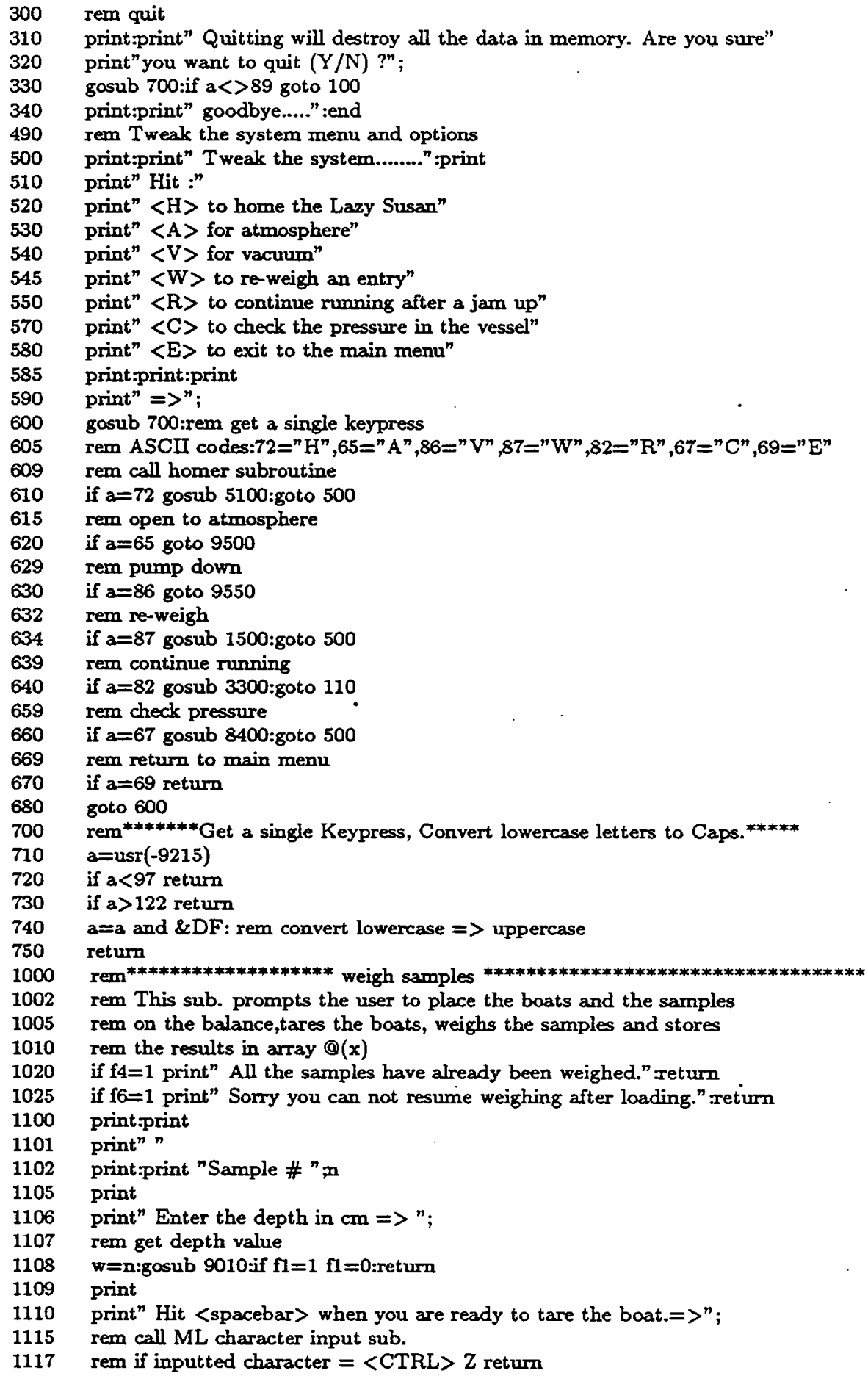




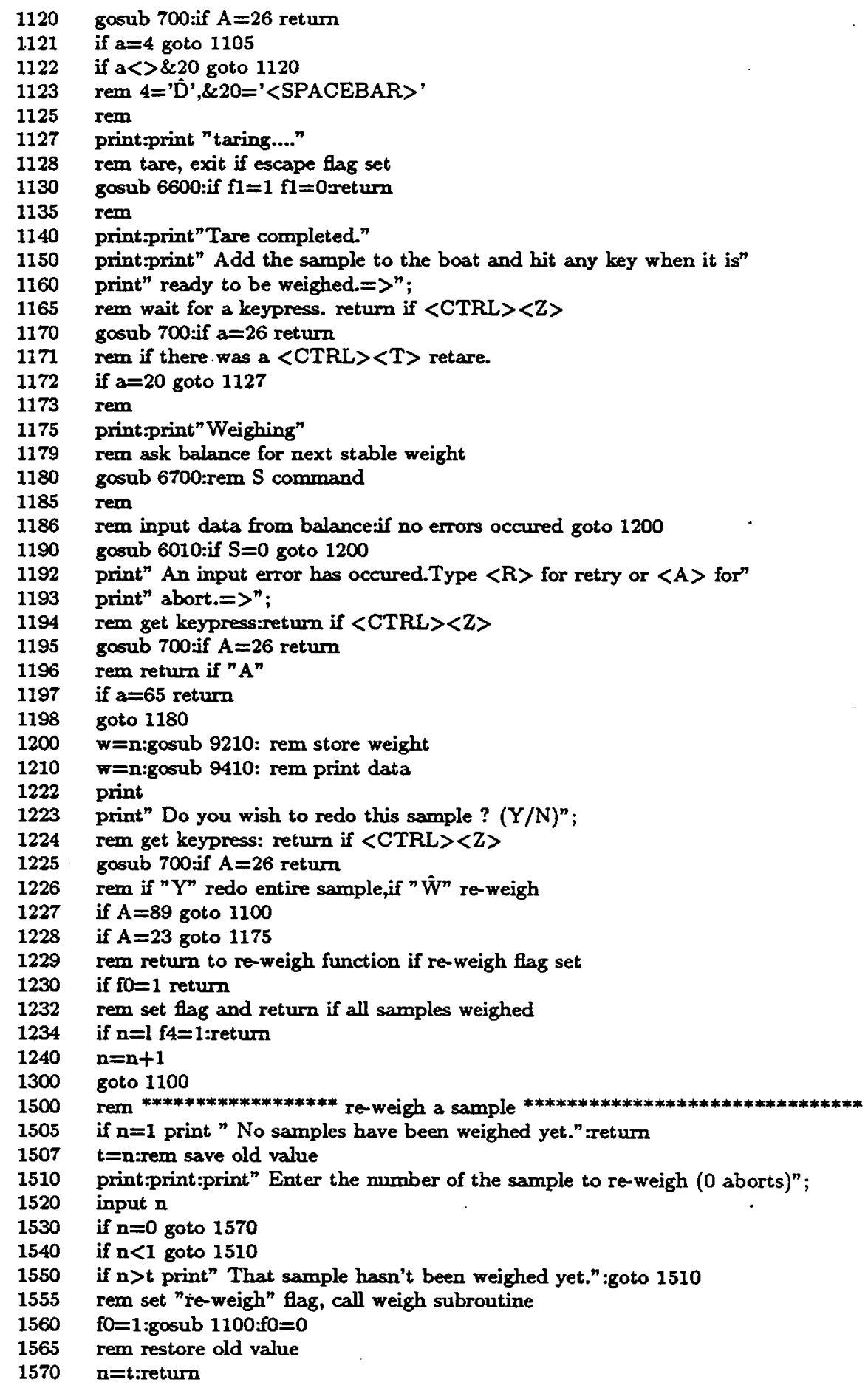




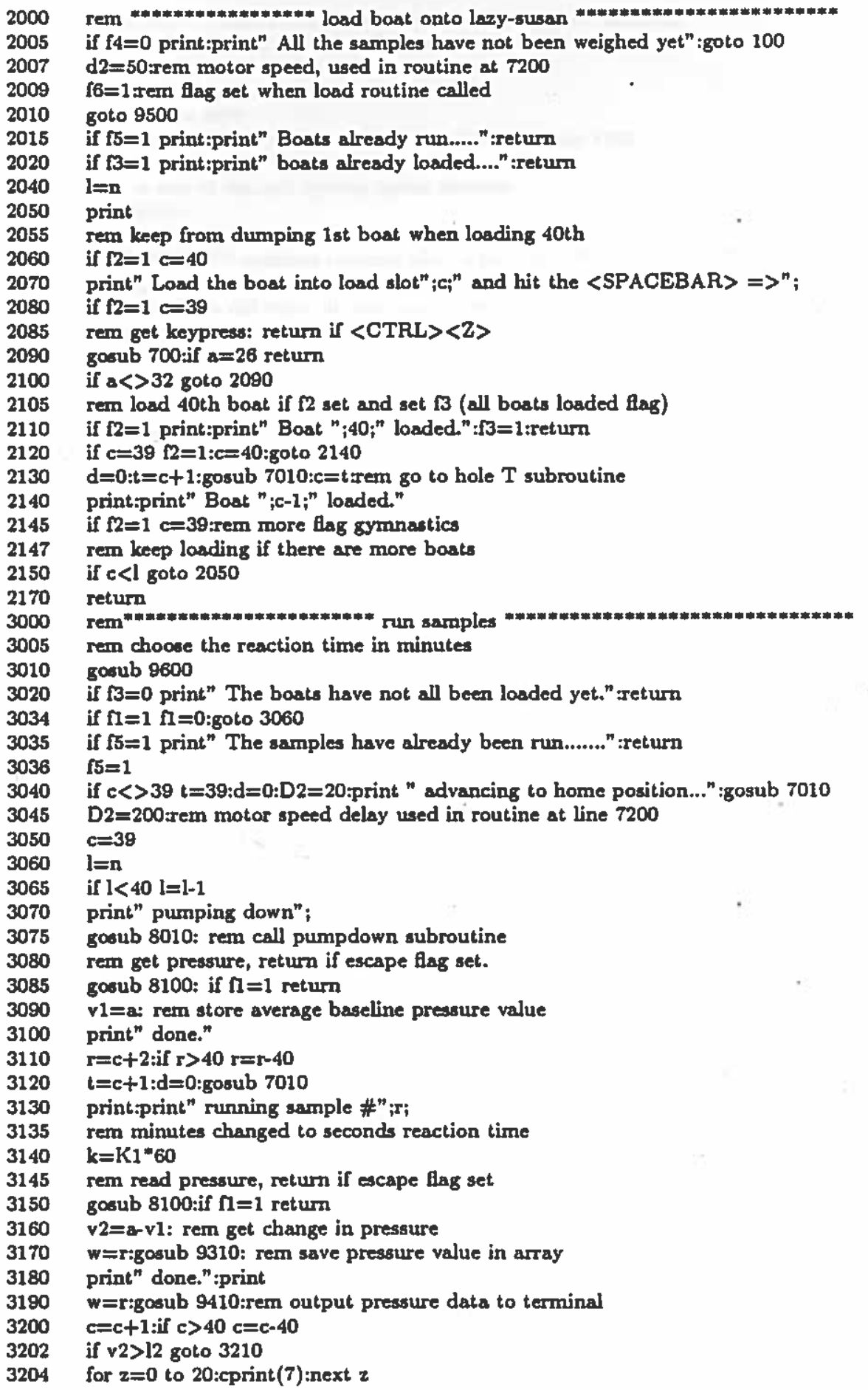


print:print" Check to make sure the Lary-suann isn't jammed."

print ${ }^{n}$ Hit $<A>$ to abort or $<R>$ to resume $=>$;

gosub 700jif $a=65 \mathrm{a}=1$ return

if $\mathrm{a}<>82$ goto 3208

if $\mathrm{r}<1$ goto 3070

if $c<>1$ print" advancing to load slot \#1...." :gosub 7100

$c=1$

rem at end of run put syatem under vacuum goto 9550

return

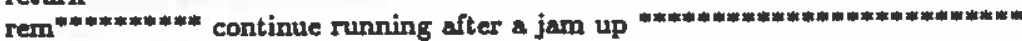

print-print

$t=c$ rem save old value in case user aborts

print " Enter the \# of the load slot the L.S is homed to (0 to abort) ";

input $c$

if $c=0$ c=tireturn

if c>40s to 3320

if $c<1$ goto 3320

$\mathbf{n = 1}$

gosub 3000

return

rem $=$ print contents of waight/presaure file

rem

if $n=1$ print:print" Sorry, there is nothing to print." return

if $n<40 n=n-1$

for $w=1$ to $\mathrm{N}$

gosub 9410

next $w$

if $\mathrm{N}<40 \mathrm{~N}=\mathrm{N}+1$

goab 700 rem wait for a key preas

return

rem

print.print" CAUTION: re-initializing will destroy all the"

print" data in memory. Are you sture you want to do it $(\mathrm{Y} / \mathrm{N})$ ?" $^{n}$;

gosub 700:if $a<>\& 59$ goto 110

print:print" Forgetting

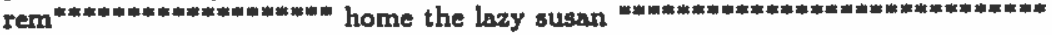

if $\mathrm{r}=1$ print:print:print" CAUTION; boats have already been loaded!"

printaprint:print" Home Menu"

print.print

print $^{n}<$ FIGHT ARROW > = counter clockwise"

print" $<$ LEFT ARROW > = cloctwise"

print" < DOWN ARROW > = single step mode"

print" $<$ UP ARROW > = continuou step mode"

print $^{n}<\mathrm{S}>$ = Smart Home option"

print $^{n}<\mathrm{E}>=$ exit $^{n}$

print:print $"=>$;

gosub 700: rem get a single keypress

rem $7=$ mode tag, $0=$ single step mode, $1=$ contintuous step mode

out 01,64rem send stop command to motor controller card

if $a=10 ~ \eta 7=0:$ rem when booted under Asyne

if $a=24 \Gamma 7=0 ;$ rem when booted under Word Star

if $a=11 \mathrm{f}=1:$ rem Async

if $a=5 \quad 7=1: \operatorname{rem} W S$

if $\mathrm{a}=29 \mathrm{~d}=1$ :gosub 5500:rem Asyne

if $\mathrm{a}=19 \mathrm{~d}=1$ :gosub 5500:rem WS

if $a=12 d=0 ;$ gosub 5500:rem Async 
5410

5415

5420

5425

5430

5440

5500

5510

5520

5530

$\mathbf{5 5 5 0}$

$\mathbf{5 5 5 5}$

5560

5570

5600

5602

5604

5610

5700

5710

5712

5714

5720

6000

6010

6020

6030

6040

6050

6060

6070

6080

6090

6100

6110

6120

6130

6140

6150

6160

6170

6180

6190

6200

6220

6230

6240

6250

$62 B 0$

6270

6280

6290

6300

6310

6320

6330

if $a=4 \mathrm{~d}=0$ :gasub $5500 \mathrm{rem}$ WS

rem smart home option

if $\mathrm{a}=\mathbf{8 3}$ goto 5600

rem return to other menu

if $\mathrm{a}=69$ goto 5700

goto 5310

rem send commands to motor controller card

if $\mathbf{~} \mathbf{7}=1$ goto $\mathbf{5 5 5 0}$

otit 01,68 or $\left(d^{*} 8\right)$ : rem single step,direction d

return

out 01,69 or $\left(D^{*} 8\right)$ : rem continuous step mode, direction d

out 00,254 : rem motor speed

return

rem" smart home option

print.print" Enter the current load slat \# "iinput c

if $c<1$ gato 5600

if c> 40 goto 5600

gosub 7100:return

rem" return to main menu

print:print" Enter the current load slot \# ";:input c

if $c<1$ goto 5720

if e> 40 goto 5710

return

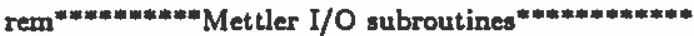

rem Generic input subroutine

rem This routine calls a $\mathrm{m} / \mathrm{l}$ routine to input data from the Mettler rem and sets the flag $S$ on the result.

rem if $S=0$ the data was succesfully inputed and is stored in $\operatorname{ren} \oplus(0)-\oplus(15)$

rem if $S=1$ a tare occurred and the data in $0(0)-(15)$ is invalid

rem if $S=2$ no tare oceured and no dats was received

$S=0$

rem clear out input subroutines bufier

for $Z=0$ to 15

POKE - $8201+27+2,32$

next 2

rem call machine language Mettler $\mathrm{I} / \mathrm{O}$ subroutine

$A=U S R(-9201)$

ren take dala from input subroutine's buffer $\&$ put it in $\Phi(0)-(15)$

for $\mathrm{Z}=0$ to 15

$(Z)=$ PEEK $(-9201+27+Z)$

next 2

rem check to see if first data byte valid ( $\& 53=" S^{\prime \prime}$ )

if $(0)=\& 53$ goto 6260

rem first byte isnt the start of a data block:goto interpret ertor sub goto 6280

rem check to see if last byte valid $(\& A=<I I>)$.if so assume

rem the whole data block is valid

if $\oplus(15)=\&$ A return

rem find location of $\langle 1 \mathrm{l}\rangle$ in array $\theta(X)$

for $Z=0$ to 15

if $(\mathrm{C}(\mathrm{Z})=\& \mathrm{~A}$ goto 6340

next $\mathrm{Z}$

rem if no <lf> found set error flag and return

$S=2$ return

rem check first char of message CASE " $\mathrm{T}^{\prime \prime}->6400$ 


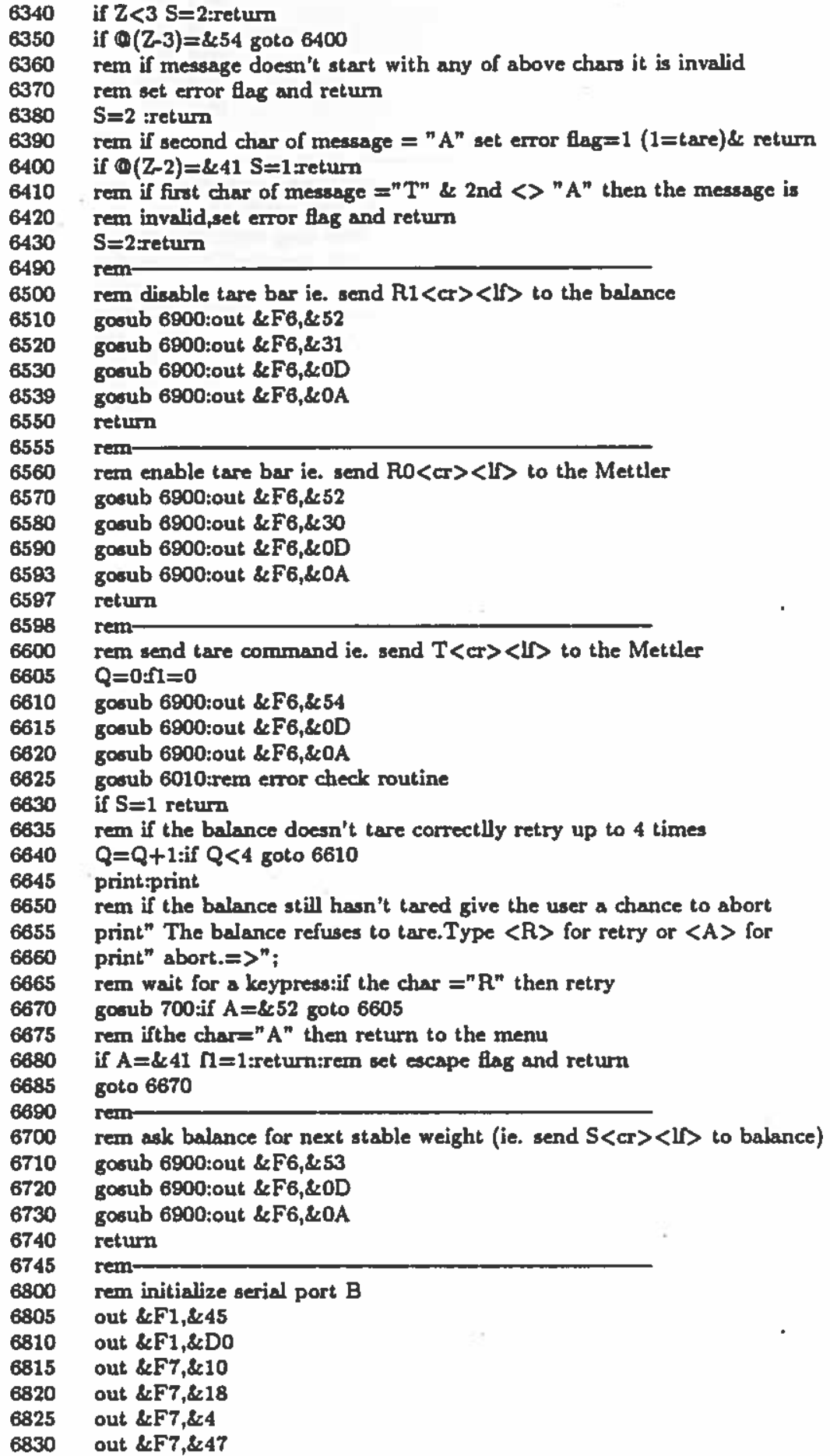




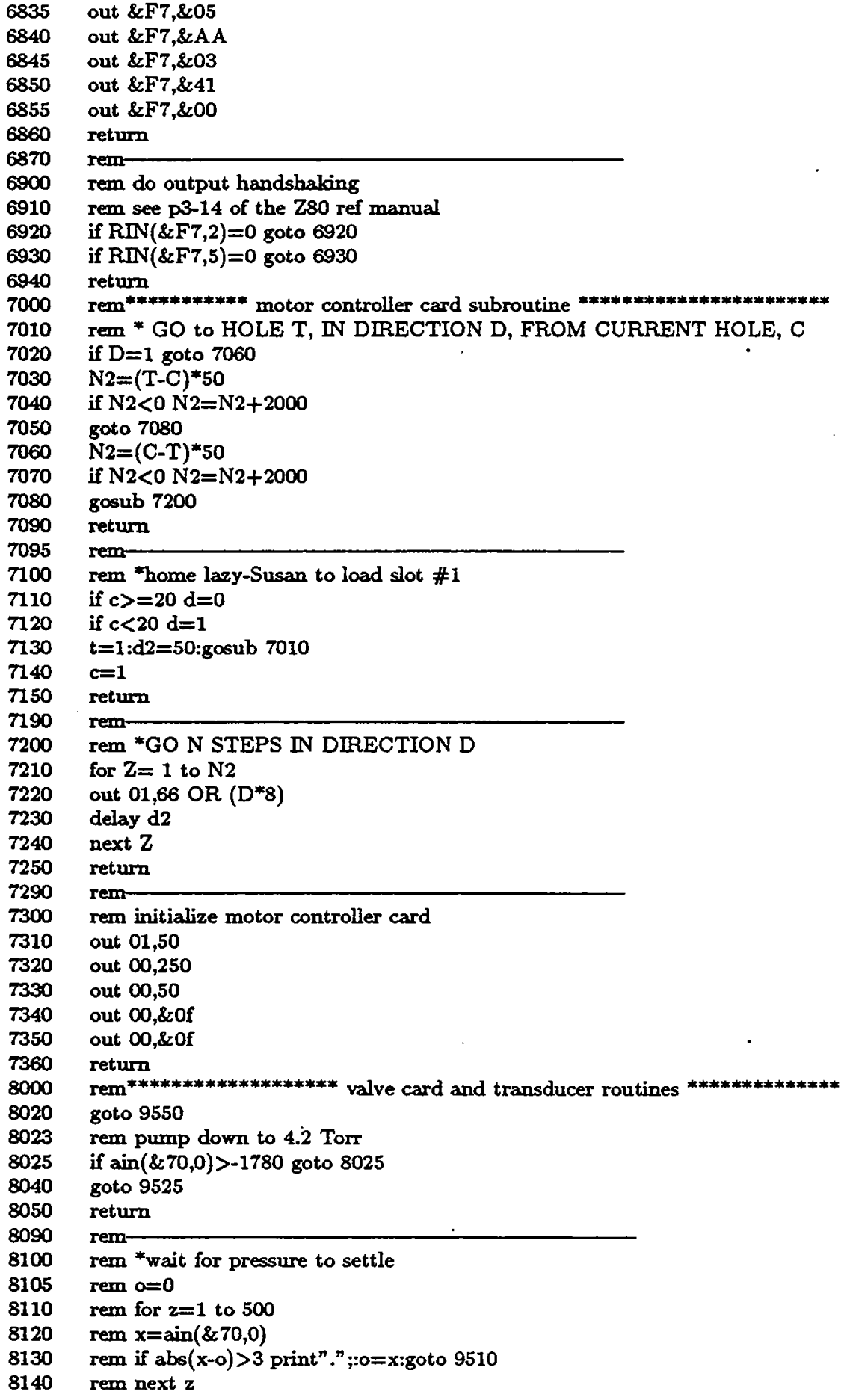


rem * average data from pressure transducer rem by making sure 10 values in a row are equal rem with a delay of 6 seconds between each reading b1 $=\operatorname{ain}(\& 70,0)$ if $\operatorname{ain}(\& 70,0)>16000$ goto 8260 $\mathrm{b}=0$ delay 6000 b2 $=\operatorname{ain}(\& 70,0)$ if $a b s(b 2-b 1)>6$ goto 8205 $\mathbf{b}=\mathbf{b}+1$ if $b<9$ goto 8215 $a=b 1$ return out 120,0:delay 3000: rem close all valves print" The reaction chamber is open to the atmosphere." print" $<P>$ umpdown or <A > bort ?"; gosub 700

if $a=65 \mathrm{fl}=1$ return

if $a=80$ out 120,2 :delay 3000 :goto 8205 goto 8265

rem delay $\mathbf{k}$ seconds

for $m=1$ to $k$

delay 1000

next m

return

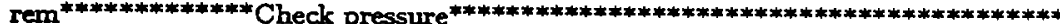

gosub 9550:rem close valves/pumpdown subroutine

print "Pumping on the acid for 36 seconds";

delay 9000:delay 9000:delay 9000:delay 9000

gosub 9525:rem close all valves

print:print" Enter time interval in seconds (0 aborts) "; input $\mathbf{k}$.if $\mathbf{k}<0$ goto 8410 print:" Getting initial pressure (1 minute)..."; if $\mathbf{k}=0$ return gosub 8100: v1=a: rem get initial pressure print " Waiting ";k;" seconds......."; gosub 8300: rem wait $k$ seconds print: "Getting final pressure (1 minute)...."; gosub 8100: rem get pressure again print" The change in pressure was ";v1-a;" digital units." gosub 9550:rem continue pumping on acid return

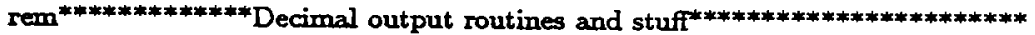
rem This routine takes the var. $Z$ and creats a rem 5 byte string of \#'s, containing the the ASCII codes for the rem characters which make up the printed representation of the \# $Z$ rem and stores them in $\mathrm{J}(0)-\mathrm{J}(4)$

for $X=0$ to $4: J(X)=32$ :next $X$ $Q=1: P=10000$

rem if $Z$ is negative then $J(0)=45$ (45=the ASCII code for "-n)

if $\mathrm{ABS}(\mathrm{Z})<>\mathrm{ZJ}(0)=45: Z=A B S(Z)$

$\mathrm{J}(\mathrm{Q})=\mathrm{MOD}(\mathrm{Z}, \mathrm{P}) /(\mathrm{P} / 10)+\& 30$

if $\mathrm{P}=10$ goto 8700

$P=P / 10$

$\mathrm{Q}=\mathrm{Q}+1$

goto 8600 .

rem remove leading 0 's and replace w Ath spaces 


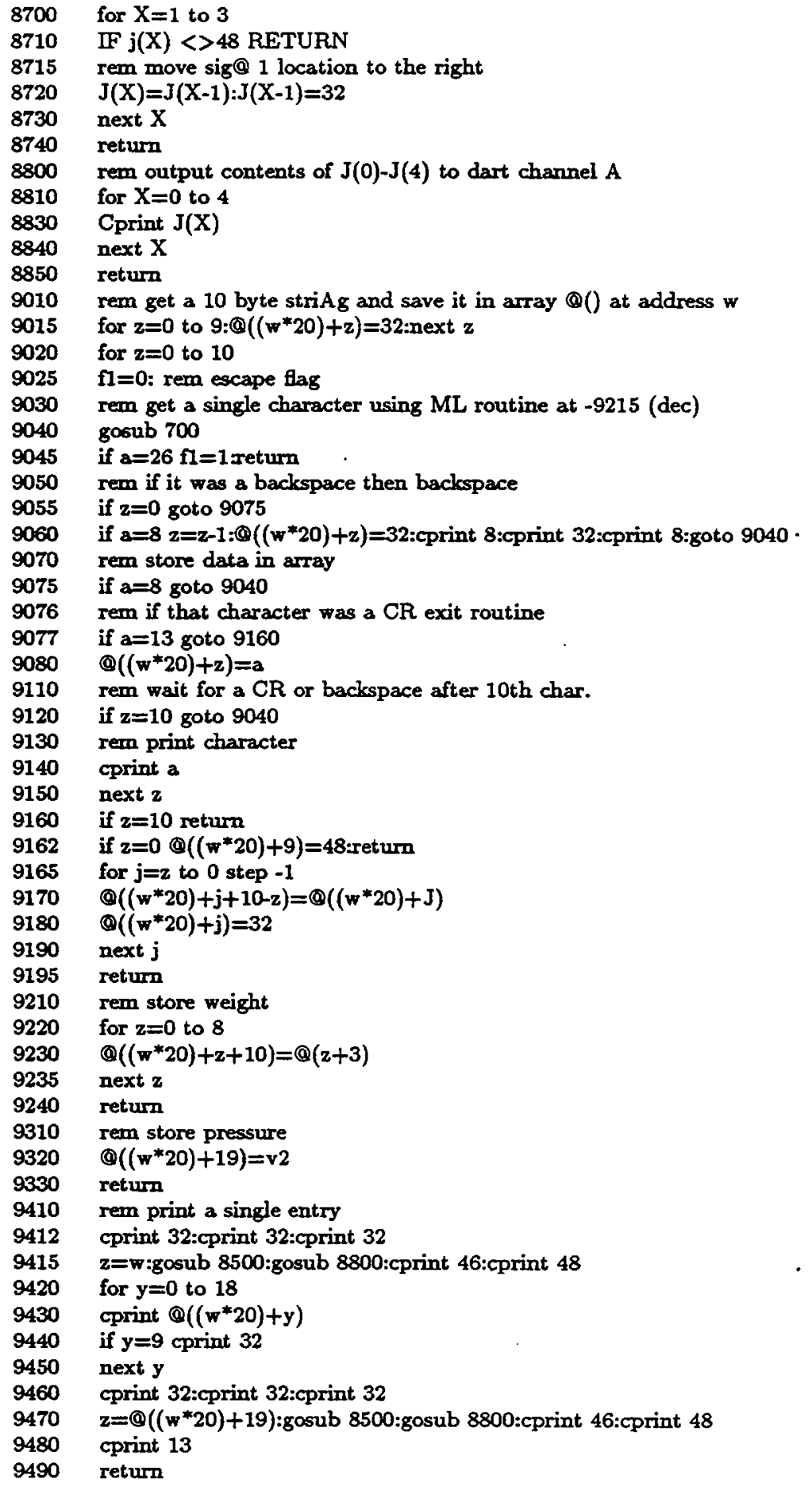


rem $* * * * * * * * * * * * * * *$ open to atmosphere subroutine of $^{* * * * * * * * * * * * * * *}$

rout $112,2,0$

rout $112,3,0$

delay 1000:rout $112,2,1$

return

rem ********************* close all valves subroutine $\mathrm{e}^{* * * * * * * * * * * * * *}$

rout $112,2,0$

rout $112,3,0$

delay 3000

return

rem $* * * * * * * * * * * * *$ close valves/pumpdown subroutine $\mathrm{e}^{* * * * * * * * * * * * * * * * * * * *}$

rout $112,2,0$

rout $112,3,0$

delay 3000:rout $112,3,1$

return

rem****************** reaction time menu ${ }^{* * * * * * * * * * * * * * * * * * * * * * *}$

print:print " Run the system............." :print

print "Choose the appropriate reaction time ":print

print " Hit: "

print " $<\mathrm{L}>$ low carbonate ( 0-25\%), 20 minutes"

print " $<\mathrm{H}>$ high carbonate (25-100\%), 5 minutes"

print:print:print

print " $=>$ ";

gosub 700: rem get a single keypress

rem ASCII codes: $72={ }^{\prime} H^{\prime}, 76=' L ', 77=' M$ '

rem low carbonate

if $\mathrm{a}=76 \mathrm{~K} 1=20$ :goto 9800

rem high carbonate or standards

if $\mathrm{a}=72 \mathrm{~K} 1=5$ :goto 9800

return

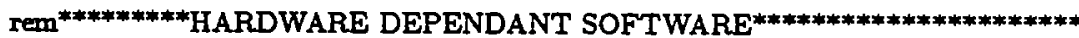

rem

rem There are a few hardware dependant lines in Animat.bas

rem which will have to be changed if the hardware is

rem configured differently. The lines are listed below and

rem are marked with a '\#' in the program listing.

rem

rem Relay output channels: 9505-9515, 9530-9535, 9555-9565

rem Analog input address : $8025,8120,8205-8207,8220$

rem Motor driver : $5330,5510-5560,7310-7350$ 
C

C

Loader.bas

This program loads two machine language subroutines into memory.

REM RDKEY \& METIO loader program, last revised 29.8.89 (DRO)

rem This program loads 2 machine language subroutines,

rem RDKEY \& METIO, into memory

rem RDKEY starts at -9215

rem METIO starts at -9201 . It's buffer starts at -9174 $\mathrm{x}=\& \mathrm{DC} 00$

$\mathrm{b} 1=\& 2 \mathrm{~A}: \mathrm{b} 2=\& \mathrm{dC}$

REM Single character input subroutine (RDKEY)

REM DB,F5 LOOP INA,F5H ;check RCV bit

REM CB,47 BIT 0,

REM 28,F9 JR Z,P ;i's not set wait

REM DB,F4 IN A,H ig character

REM E6,7F AND 7F;lose the highest bit

REM 6F L t $n$ L so basic can read it

REM 26,00 LD H,zero H so basic doesn't get garbage

REM C9 RTrn

REM poke single character input sub. into mernory

$\mathrm{X}=\mathrm{X}+1$ :POKE $\mathrm{X}, \& O D B$

$\mathrm{X}=\mathrm{X}+1:$ POKE $\mathrm{X}, \& 0 \mathrm{~F} 5$

$X=X+1: P O K E X, \& O C B$

$X=X+1: P O K E X, \& 047$

$X=X+1: P O K E X, \& 028$

$X=X+1: P O K E X, \& O F 9$

$X=X+1: P O K E X, \& O D B$

$\mathrm{X}=\mathrm{X}+1: P O K E \mathrm{X}, \& 0 F 4$

$X=X+1: P O K E X, \& O E 6$

$\mathrm{X}=\mathrm{X}+1:$ POKE $\mathrm{X}, \& 07 \mathrm{~F}$

$\mathrm{X}=\mathrm{X}+1: P O K E \mathrm{X}, \& 06 \mathrm{~F}$

$X=X+1: P O K E X, \& 026$

$X=X+1: P O K E X, \& 000$

$\mathrm{X}=\mathrm{X}+1: P O K E \mathrm{X}, \& 0 \mathrm{C} 9$

REM Balance input subroutine (METIO)

REM b1 and b2 are variables

REM 06,10 START LD B,16 16=the maximum \# of chars.

REM DD,21,b2,b1 LD IX,\$b1b2 load IX with start of buffer

REM DB,F7 LP IN A,(\$F7) load A with status register

REM CB,47 BIT 0,A test bit 0 (bit=0 RCV flag)

REM 28,FA JR Z,LP if it=0 goto LP

REM DB,F6 IN A,(\$F6) load a with data register

REM E6,7F AND 7F

REM DD,77,00 LD (DX),A store A in buffer

REM DD,23 INC IX increment buffer pointer

REM FE,OA CP $\$ A$ compare A to $10(10=l f)$

REM C8 RET $Z$ if equal return to BASIC

REM 10,EC DJNZ LP decrement $B$ and goto LPifnoto

REM C9 RET if $b=0$ (ie. 16 chars.have been

REM entered) return to BASIC

REM \&F7 = the status register of DART channel b

REM \&F6 = the data register of the same.

REM See pp 3-8 - 3-17 of the MULTIFUNCTION Z80CPU CARDS VL-7806 \&VL-7807

REM for more info. on the dart chip. esp 3-14 
Loader.bas continued.

460 rem poke balance input subroutine into memeory

$470 \mathrm{X}=\mathrm{X}+1$ :POKE X,\&06

$480 \quad X=X+1: P O K E X, \& 10$

$490 \quad X=X+1: P O K E X, \& D D$

$500 \quad X=X+1: P O K E X, \& 21$

$510 \mathrm{X}=\mathrm{X}+1$ :POKE $\mathrm{X}, \mathrm{b} 1$ : rem tell $\mathrm{ML}$ program where its buffer starts

$520 \quad \mathrm{X}=\mathrm{X}+1:$ POKE $\mathrm{X}, \mathrm{b} 2$

$530 \quad \mathrm{X}=\mathrm{X}+1: P O K E \mathrm{X}, \& \mathrm{DB}$

$540 \quad X=X+1: P O K E X, \& F 7$

$550 \quad X=X+1: P O K E X, \& C B$

$560 \quad X=X+1: P O K E X, \& 47$

$570 \quad X=X+1: P O K E X, \& 28$

$580 \quad X=X+1: P O K E X, \& F A$

$590 \quad X=X+1: P O K E X, \& D B$

$600 \quad \mathrm{X}=\mathrm{X}+1$ :POKE $\mathrm{X}, \& \mathrm{~F} 6$

$610 \quad X=X+1: P O K E X, \& E 6$

$620 \quad X=X+1: P O K E X, \& 7 F$

$630 \quad X=X+1$ :POKE $X, \& D D$

$640 \quad X=X+1: P O K E X, \& 77$

$650 \quad X=X+1$ :POKE $X, \& 00$

$660 \mathrm{X}=\mathrm{X}+1: P O K E \mathrm{X}, \& \mathrm{DD}$

$670 \quad X=X+1: P O K E X, \& 23$

$680 \quad X=X+1$ :POKE $X, \& F E$

$690 \quad X=X+1: P O K E X, \& \angle O A$

$700 \quad X=X+1$ :POKE $X, \& C 8$

$710 \quad X=X+1$ :POKE $X, \& 10$

$720 \quad \mathrm{X}=\mathrm{X}+1: \mathrm{POKE} \mathrm{X}, \& \mathrm{EC}$

$730 \mathrm{X}=\mathrm{X}+1$ :POKE $\mathrm{X}, \& \mathrm{C} 9$ 
Appendix 6. System Configuration Procedure.

The system has a total of 48K RAM; three $8 \mathrm{~K}$ RAM chips on the Z80 board and three $8 \mathrm{~K}$ RAM chips on the memory expansion board. The present configuration is diagrammed in Figure 5 and is detailed as follows:

a) the storage area starts at $\& 7400$

b) the development RAM size is set to $21 \mathrm{~K}$

c) the storage area size is set to $26 \mathrm{~K}$

d) $1 \mathrm{~K}$ at the top of memory is reserved for important machine language subroutines

If your system is not configured to reserve the necessary $1 \mathrm{~K}$ of memory, reinitialize the system by following the procedure outlined below:

1. Enter NOVOS by typing 'NOVOS'

2. Download clear.bas and run it (see clear.bes under SOFTWARE, p. 6)

3. Power down the system for $\mathbf{1 5}$ seconds and reset the power supply card.

4. Turn the power back on and hit ' 0 ' (zero) repeatedly until the prompt appears

5. At the prompts enter;

'21' for RAM size

' $O$ ' for baud rate

6. Type 'NOVOS'

7. Type 'SETUP'

8. At the prompts enter;

' 1 ' for memory type (CMOS RAM)

' 7400 ' for the start of the storage area

' 26 ' for the storage area size

' 5 ' for the number of directory entries

9. Download loader.bas and run it (see loader.bas under SOFTWARE p 7.)

10. Download animat.bas and fix the downloading errors if any

11. Save animat.bas in slot 1 of the directory by typing 'SAVE 1'

12. Check to see that the machine language subroutines are properly loaded.

Type 'PRINT USR(-9215)'<RET>

Hit the space bar

' 32 ' should be printed on the screen (32 is the ASCII code for 'space bar')

If not, run loader.bes and begin from step 9

13. Type 'DIR' to see that the following is printed:

*DIR

1 AUTOMATED CARBONATE SYSTEM program, last revised 16.5.89 (DRO)

2 RDKEY \& METIO LOADER program, last revised 26.8.89 (DRO)

RDKEY and METIO should now be resident in memory, starting at \&DC01 (-9201) decimal. The execution addresses are -9215 for RDKEY and -9201 for METIO. METIO'S buffer, containing the character string inputed from the balance, begins at -9174 and is 16 bytes long. Whenever the system is powered up, always first run the loader program ('run 2') followed by the AUTOMATED CARBONATE SYSTEM program ('run 1') to assure that RDKEY and METIO are properly loaded. 
Appendix 7. Sample carousel load slot diagram.
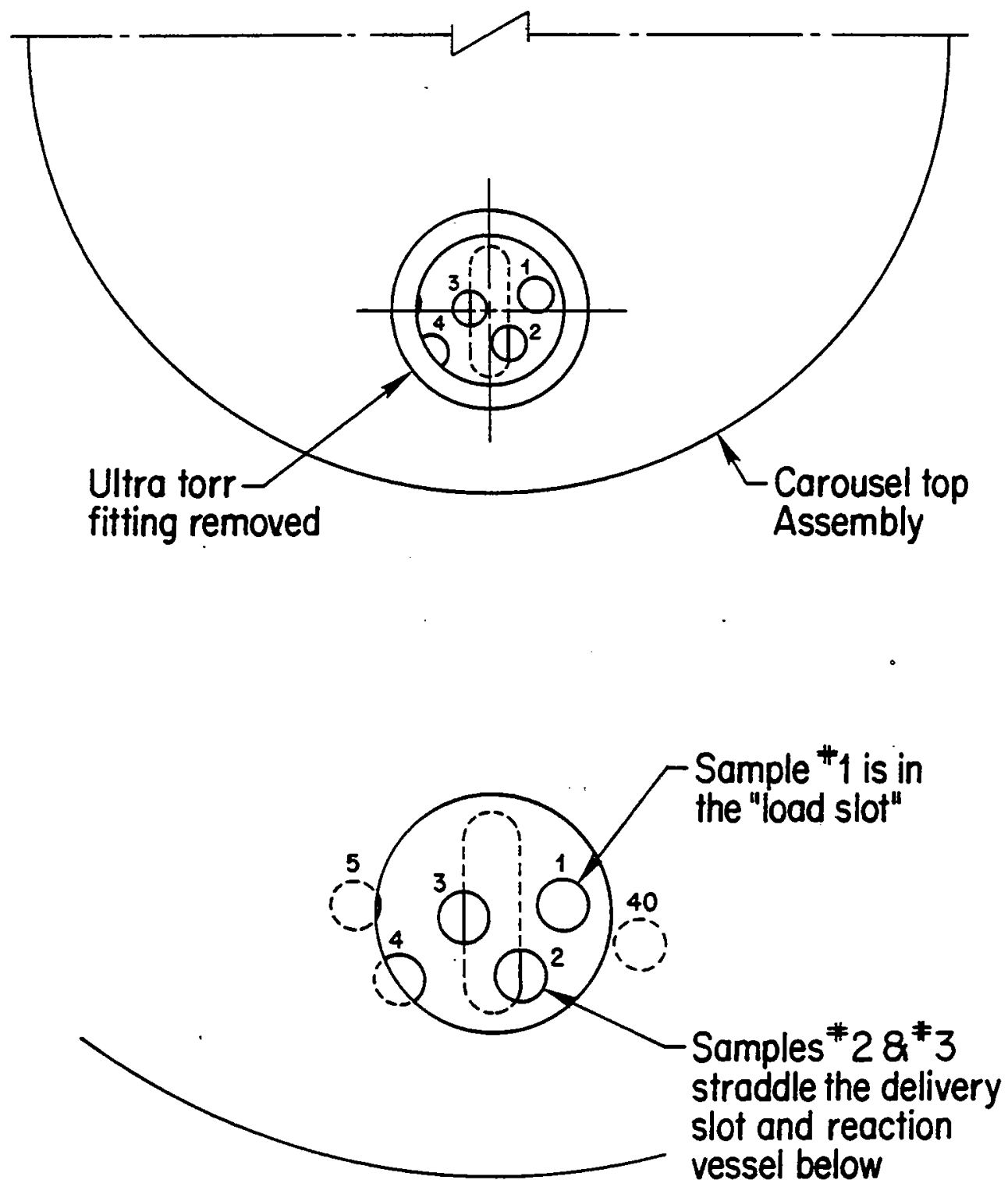
Appendix 8. Possible suppliers of equipment for the ACS

\begin{tabular}{|c|c|}
\hline COMPANY & SPECIFIC SUPPLIES NECESSARY \\
\hline $\begin{array}{l}\text { Acculex } \\
440 \text { Myles Standish Blvd. } \\
\text { Taunton, MA } 02780\end{array}$ & \#DP-654 Voltage input meter \\
\hline $\begin{array}{l}\text { Ace Glass Inc. } \\
1430 \text { N.W. Blvd } \\
\text { Vineland, NJ } 08360-688\end{array}$ & \#9519-10 Pinch elamp for $25 \mathrm{~mm}$ joint \\
\hline $\begin{array}{l}\text { All-Stainless } \\
75 \text { Research Rd. } \\
\text { Hingham, MA 02043 }\end{array}$ & $\begin{array}{l}10-32 \times 3 / 8 \text { " allen cap screws } 18-8 \text { s.s. } \\
10-32 \times 2^{\prime \prime} \text { allen cap screws } 18-8 \text { s.s }\end{array}$ \\
\hline $\begin{array}{l}\text { Analog Devices } \\
1 \text { Technology Way } \\
\text { Norwood, MA 02062.9106 }\end{array}$ & $\begin{array}{l}\text { chaseis mounted ac/dc power supply } \\
+/ \cdot 15 \text { vdc output } \# 952\end{array}$ \\
\hline $\begin{array}{l}\text { Anderson Glass } \\
\text { Old Turnpike Rd. R.F.D. } 1 \\
\text { Fitzwilliam, NH } 03147\end{array}$ & glass reaction ressel; see Appendix 3. \\
\hline $\begin{array}{l}\text { \& D Motor Control Corp } \\
\text { 99 Lowell Road } \\
\text { Hudson, NH } 03051\end{array}$ & Slo-Syn DC stepping motor \#MO61-FD-3I1 \\
\hline $\begin{array}{l}\text { Cambridge Valve \& Fitting } \\
50 \text { Manning Rd. } \\
\text { Billerica, MA } 01821\end{array}$ & $\begin{array}{l}\text { Cajon ultra-torr union fiting } 1 / 2^{\prime \prime} \text { to } 1 / 4^{n} \text { \#SS-8-UT-6-4 } \\
\text { Cajon ultra-torr fitting \#SS-16-UT-A-20 } \\
\text { Cajon ultra-torr union fiting } 1 / 4^{n} \text { to } 1 / 4^{n} \text { \#SS-4-UT-6 } \\
\text { Cajon tube adapter NPT Male \#B-2-MHC-45 for water bath } \\
\text { Nupro air actuator valve \#SS4-BK-1C } \\
\text { Nupro DC powered soledoid vaive \#MS-sol-1K } \\
\text { Cajon flexible tubing } 12^{\prime \prime} \# 321-4-X-12 \\
\text { Cajon lexible tubing insert \#304-4XBA } \\
\text { Cajon female } 1 / 4^{n} \text { NPT Tee \#B-4-T } \\
\text { Cajon } 1 / 4 " \text { NPT male } 1 / 4^{\prime \prime} \text { swagelok \#B-MB4-TA-1-4-24R } \\
\text { Swagelok } \times 10 / 32^{\prime \prime} \text { male \#B-400-1-0232 }\end{array}$ \\
\hline $\begin{array}{l}\text { Cole Parmer } \\
7425 \text { N. Oak Park Ave. } \\
\text { Chicago, IL } \\
60648\end{array}$ & $\begin{array}{l}378^{\prime \prime O D ~} \times 1 / 4^{\prime \prime} \text { ID Norprene tubing \#N-06410-05 } \\
\text { Plastic comprestion quick-disconnects } \\
\text { \#YA-6360-30 \& \#YA-6364-05 } \\
\text { Finnpippetse 5-50ul \#J-6247-01 }\end{array}$ \\
\hline $\begin{array}{l}\text { General Supply \& Metals } \\
47 \text { Nauset Street } \\
\text { New Bedford, MA } 02746\end{array}$ & 1/4" OD copper rod (sample boats; see appendix 4.) \\
\hline $\begin{array}{l}\text { Eallmark Electronics } \\
6 \text { Cook St. Pinehurst Park } \\
\text { Billerica, MA } 01821\end{array}$ & 8K Non-voltite ram chips \#DS1225Y \\
\hline $\begin{array}{l}\text { Lambda Electronics } \\
515 \text { Broad Hollow Rd. } \\
\text { Melville, NY } 11746\end{array}$ & Power supply 0.40 VDC \#LQ-412 \\
\hline $\begin{array}{l}\text { Matrix Corp. } \\
1203 \text { New Hope Rd. } \\
\text { Raleigh, NC } 27610\end{array}$ & $\begin{array}{l}\text { Stepping Motor control card for STD bus \#7911/SSC-5K } \\
\text { Unipolar motor driver card \#7911/usd } \\
\text { RCA/26 cable so connees SSC to USD }\end{array}$ \\
\hline $\begin{array}{l}\text { Mettlex Inst. Corp. } \\
\text { Box } 71 \\
\text { Hightstown, NJ } 08520\end{array}$ & \#012 bi-directional data interface for $\mathrm{AE}$ balance \\
\hline $\begin{array}{l}\text { Microgroup } \\
7 \text { Indust rial Park Rd. } \\
\text { Medway, MA 02053 }\end{array}$ & $\begin{array}{l}304 \text { low carbon seamless s.s. tubing } \\
1 / 4^{\prime \prime} \text { OD } \times .060^{\prime \prime} \text { ID } \times .095^{\prime \prime} \text { wall } \\
\text { Military specs } .021 \% \text { carbon }\end{array}$ \\
\hline $\begin{array}{l}\text { MKS Instruments } \\
6 \text { Shattuck Rd. } \\
\text { Andover, MA } 01810\end{array}$ & $\begin{array}{l}\text { Absolute pressure transducer \#122AA-00100-AB } \\
\text { a-100 Torr; } 1 / 2^{n} \text { tubulation with standard } \\
\text { accuracy plus cable and connector }\end{array}$ \\
\hline $\begin{array}{l}\text { Newark Electronics } \\
\text { Route } 1 \text { South Park } \\
\text { Walpole, MA 02081 }\end{array}$ & $\begin{array}{l}26 \text { pin female edge connector assembly \#FCE-26-103 } \\
26 \text { pin flat cable connector with polarity bump \#S2J026 } \\
26 \text { conductor flat laminated cable \#36F658WA }\end{array}$ \\
\hline $\begin{array}{l}\text { Poly Seiences Corp. } \\
7800 \text { Merrimac A ve. } \\
\text { Niles, IL } 60648-48312\end{array}$ & Circulasing water bash \#1.060-700 \\
\hline $\begin{array}{l}\text { Versalogic } \\
3888 \text { Stewart Road } \\
\text { Eugene, OR } 97402\end{array}$ & $\begin{array}{l}\text { 64K ram memory expansion board \#VL-7709A } \\
\text { Z-80 procesor card for STD bus \#VL-7806C } \\
\text { C4 Basic/Novos ROM for VL-7806 \#2066 } \\
\text { STD-Ain-1A analog input card \#2370 } \\
\text { Power supply card \#VL-PSC } \\
8 \text { channel relay output card \#VI-IPI-2 } \\
\text { Transformer \#PSC-2532 } \\
9 \text { slot card cage with backplate \#VX-09T-MB } \\
\text { \#8560 26 pin to D8-25S cable } \\
\text { \#9553 D8-25S to D8.25S cable (for serial connection) }\end{array}$ \\
\hline $\begin{array}{l}\text { VWR Scientific } \\
\text { P.O. Box 232 } \\
\text { Boston, MA } 02101\end{array}$ & 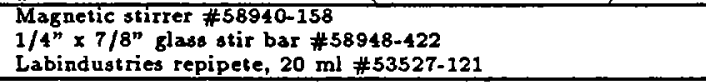 \\
\hline
\end{tabular}




\section{Appendix 9. Trouble shooting guide}

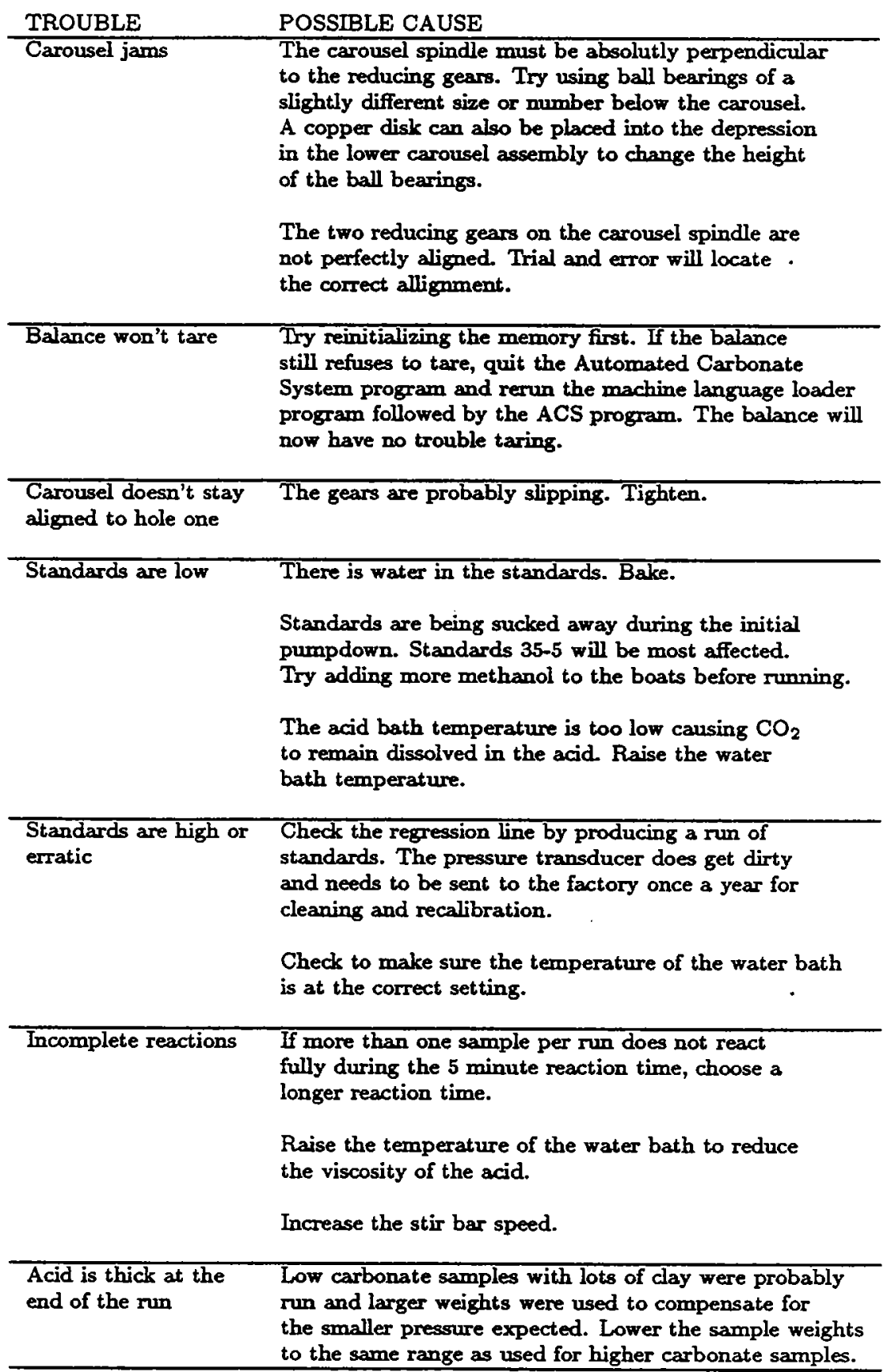


Appendix 10. System startup.

The following directions allow the user to operate the carbonate system quickly and easily. For more detailed information, refer to the technical manual.

1. Make sure the compressed air source is on and adjusted to 80 psi.

2. Turn on the stepping motor power supply making sure either the $(+)$ or the $(-)$ terminal lead is not connected.

3. Once the voltage stabilizes at $28 \mathrm{VDC}$, plug in the unattached lead. If there has been a power failure, the surge protection strip will probably have to be reset.

4. Power up the NEC terminal. ASYNC should be installed in drive 'A'.

5. Power up the card cage and then push the reset button.

6. The C4 BASIC system prompt '*' should be displayed on the screen. If not, push the reset button on the card cage.

7. Type 'DIR' at the prompt to make sure the following is printed:

1. The Animating Elememt, last revised 30.08.89 (DRO)

2. RDKEY \& METIO loader program, last revised 29.08.89 (DRO)

3. GETDATA program to produce pressure/time data

8. Type 'run $2<$ RET >' (nothing will appear to happen) followed by 'run $1<$ RET $>$ '.

The following should appear:

Welcome stranger.

Skip software initialization? ( $\mathrm{Y} / \mathrm{N}$ ) : (in most cases type ' $N$ ')

Is the lazy susan homed to slot \#1? (Y/N) : (check the alignment)

9. 'The Main Menu' will now be displayed on the screen.

10. Attach the acid filled reaction vessel to the carousel.

11. Turn the circulating water bath on, checking that it is adjusted to $80^{\circ} \mathrm{C}$.

12. Turn on the spin bar mixer to a setting of 3 . 
Appendix 10. System startup continued.

13. Make sure the ULTRA-TORR fitting on the carousel is tightened.

14. Turn on the vacuum pump with the toggle switch on the surge protection strip.

15. Go to the 'Tweak the System Menu' and hit ' $V$ ' for vacuum. The acid will now begin to outgas as it is heated to temperature under vacuum.

16. Weigh out your dried/crushed sediment samples. Add methanol to each sample and dry in the oven.

17. Load the samples into the carousel. Tighten the ULTRA-TORR fitting.

18. Run the samples, choosing the appropriate reaction time.

19. At the end of the run, 'The Main Menu' will be printed on the screen. Make sure there is a floppy disk inserted in drive ' $\mathrm{B}$ '.

20. Type “- VF <RET>' : ('File specification:' will appear on the screen)

21. Type 'B:filename.crb $<$ RET>' : (The file will be copied to drive ' $\mathrm{B}$ ')

22. Type "VG<RET>' : ('port open' will appear on the screen)

23. Hit ' $\mathrm{P}$ ' and the contents of the carbonate system memory will be printed to the screen one line at a time.

24. When all 40 lines of data have been printed, type " $\mathrm{Z}<\mathrm{RET}>$ '. 


\section{DOCUMENT LIBRARY}

January 17, 1990

\section{Distribution List for Technical Report Exchange}

Attn: Stella Sanchez-Wade

Documents Section

Scripps Institution of Oceanography

Library, Mail Code C-075C

La Jolla, CA 92093

Hancock Library of Biology \& Oceanography

Alan Hancock Laboratory

University of Southern California

University Park

Los Angeles, CA 90089-0371

Gifts \& Exchanges

Library

Bedford Institute of Oceanography

P.O. Box 1006

Dartmouth, NS, B2Y 4A2, CANADA

Office of the International

Ice Patrol

c/o Coast Guard R \& D Center

Avery Point

Groton, CT 06340

NOAA/EDIS Miami Library Center

4301 Rickenbacker Causeway

Miami, FL 33149

Library

Skidaway Institute of Oceanography

P.O. Box 13687

Savannah, GA 31416

Institute of Geophysics

University of Hawaii

Library Room 252

2525 Correa Road

Honolulu, HI 96822

Marine Resources Information Center

Building E38-320

MIT

Cambridge, MA 02139

Library

Lamont-Doherty Geological Observatory

Columbia University

Palisades, NY 10964

Library

Serials Department

Oregon State University

Corvallis, OR 97331
Pell Marine Science Library

University of Rhode Island

Narragansett Bay Campus

Narragansett, RI 02882

Working Collection

Texas A\&M University

Dept. of Oceanography

College Station, TX 77843

Library

Virginia Institute of Marine Science

Gloucester Point, VA 23062

Fisheries-Oceanography Library

151 Oceanography Teaching Bldg.

University of Washington

Seattle, WA 98195

Library

R.S.M.A.S.

University of Miami

4600 Rickenbacker Causeway

Miami, FL 33149

Maury Oceanographic Library

Naval Oceanographic Office

Bay St. Louis

NSTL, MS 39522-5001

Marine Sciences Collection

Mayaguez Campus Library

University of Puerto Rico

Mayagues, Puerto Rico 00708

Library

Institute of Oceanographic Sciences

Deacon Laboratory

Wormley, Godalming

Surrey GU8 5UB

UNITED KINGDOM

The Librarian

CSIRO Marine Laboratories

G.P.O. Box 1538

Hobart, Tasmania

AUSTRALIA 7001

Library

Proudman Oceanographic Laboratory

Bidston Observatory

Birkenhead

Merseyside L43 7 RA

UNITED KINGDOM 


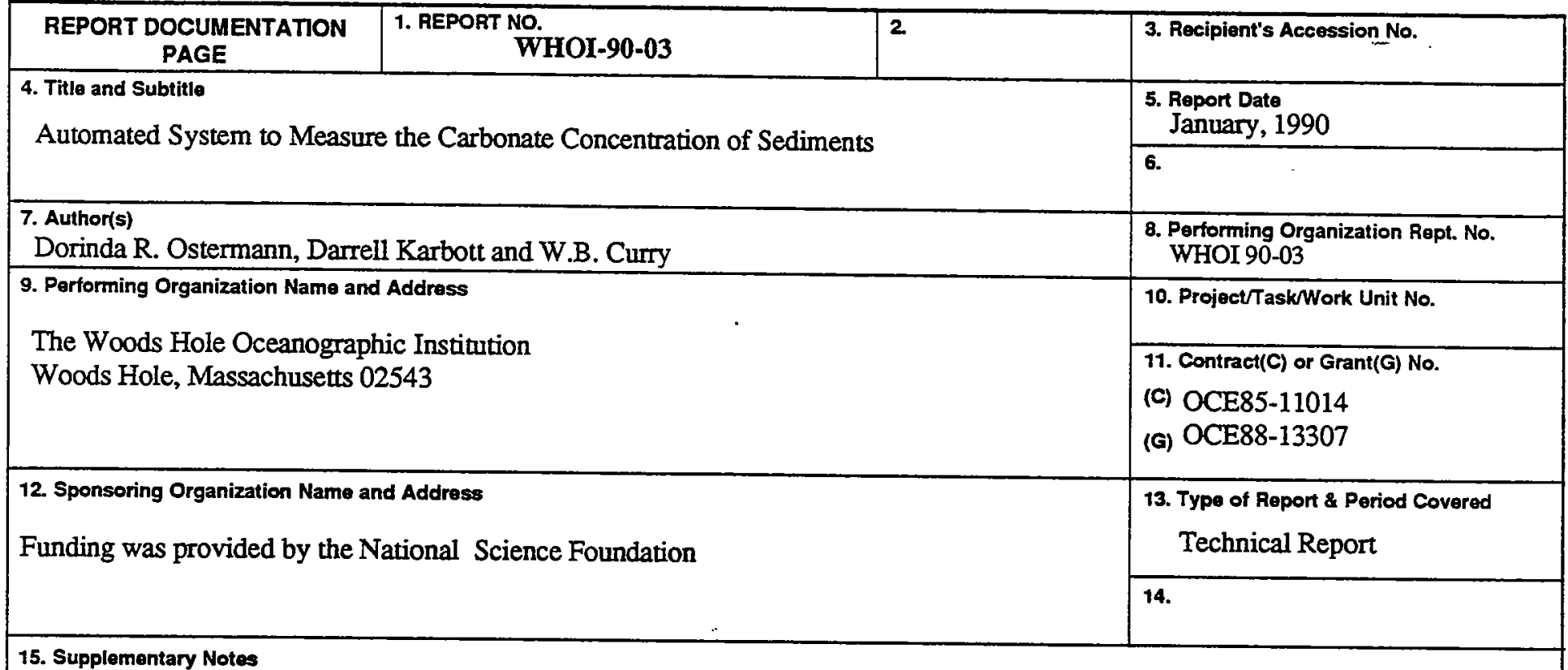

This report should be cited as: Woods Hole Oceanog. Inst. Tech. Rept., WHOI-90-03.

\section{Abstract (Limit: 200 words)}

We have developed a computer controlled system to measure the calcium carbonate content of sediment samples. A menu driven program controls the analysis of each sample. The system first communicates with a Mettler digital balance to record the weights of the 40 samples which must be loaded into each run. The sample boats are next loaded into the sample carousel which is then sealed from the atmosphere. The system is first pumped down to a vacuum of 0.04 torr. The valve to the pump closes and the stepping motor turns the carousel, moving a sample boat over the delivery slot and dropping the sample into $80^{\circ} \mathrm{C} 100 \%$ phosphoric acid under vigorous spinning action. During the reaction, carbonate is evolved into $\mathrm{H}_{2} \mathrm{O}$ and $\mathrm{CO}_{2}$ and the resulting pressure change within the closed system is measured by a pressure transducer and recorded into memory next to the sample identification and sample weight. The system is pumped once again to 0.04 torr and the process continues until all 40 samples have been analyzed. The data can then be uploaded and converted to percent carbonate values using a regression line produced from multiple analyses of varying weights of a $100 \%$ carbonate standard. Precision of the system, based upon 120 replicate analysis ranges from $0.49 \%$ to $0.88 \%$.

\section{Document Analysis a. Descriptors}

1. carbonate

2. automated

3. sediments

b. Identifiers/Open-Ended Terms

c. COSATI Field/Group

18. Availability Statement

Approved for publication; distribution unlimited.

$$
\begin{aligned}
& \text { 19. Security Class (This Report) } \\
& \text { UNCLASSIFIED }
\end{aligned}
$$

20. Security Class (This Page)
21. No. of Pages 17

22. Price 